Department of Investment

Risk Management \& Insurance

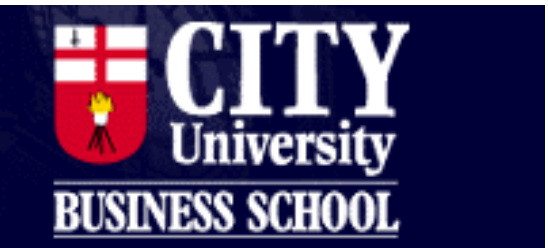

Frobisher Crescent

Barbican Centre

London

EC2Y 8HB

Tel No:

02074778694

Fax No:

02074778885

E-mail:

irmi@city.ac.uk

\title{
Integrated Risk Management
}

\author{
John W Hawkins
}

\section{September 2000}

\section{Supervisor: Professor Gerry M Dickinson}

Dissertation for

MSc in Insurance and Risk Management

Full-time program 1999/2000 
"In order to carry out great enterprises, one must live as if one will never die." Marquis de Vauvenargues, 1715-1747, Réflexions et Maximes. 


\section{Abstract \\ Integrated Risk Management}

A review and analysis of the meanings of enterprise risk management and integrated risk management, the theoretical benefits to be derived from the use of these approaches to risk management, some products and applications of an integrated risk management approach and the views of some practitioners.

The first objective of this study was to try to determine whether there was yet a consensus on the use of the terms 'enterprise risk management' and 'integrated risk management', along with their variants.

Having determined that such a consensus does not really exist, working definitions of these terms are proposed and the theoretical and regulatory cases for enterprise risk management (the management of all the risks facing an enterprise on a comprehensive and holistic basis) and integrated risk management (the management of financial and/or insurable risks on an integrated basis) are reviewed, along with the place of insurance in corporate finance theory and certain aspects of insurance linked securities.

Theoretical examples are given of the benefits likely to be derivable from an integrated risk management approach and descriptions provided of integrated risk management products available and published descriptions of their use. The likely providers of integrated risk management products are evaluated and structural implications for companies considered.

A summary is then provided of structured interviews with several sophisticated risk management practitioners and advisers concerning the impact of the Turnbull Guidelines and progress in the use and application of integrated risk management products.

The study concludes with a summary of key issues and some suggestions for further research.

$\odot$ John W Hawkins, 2000 


\section{Preface}

The author would like to record his appreciation to his tutor and supervisor, Professor Gerry Dickinson, for his continued help and encouragement throughout the preparation of this dissertation and for permitting him to draw extensively from his work, both published and unpublished. Other members of the academic staff of the City University Business School have also provided valuable comments and suggestions, especially Chris Parsons. The staff at the City University Business School Cyril Kleinwort Library, the City University Library at Northampton Square, the City Business Library and the Library of the Chartered Insurance Institute were invariably helpful. To the author's surprise, several people, including a number of fellow students, volunteered to read early drafts and, without exception, provided comments that enhanced the final version; he is grateful to all of these, too many to name individually, but of course takes full responsibility for remaining errors and omissions. The author would also like to express his thanks to the following firms for making time and/or data and/or their opinions available: Aon Group Limited, Chase, Citigroup, Deloitte \& Touche, Marsh, McKinsey, PricewaterhouseCoopers, Prudential Group plc, Swiss Re, TRW Inc., United Insurance Brokers Limited and Willis.

John W Hawkins

London

$15^{\text {th }}$ September 2000
$+44(0) 2085494141$

+44 (0)7767872701

johnwh@rakshasa.demon.co.uk 


\section{Table of Contents}

$\begin{array}{llc}\text { Abstract } & & \text { Page } \\ \text { Preface } & & 2 \\ \text { Contents } & & 3 \\ \text { Introduction } & & 4 \\ \text { Chapter1 } & \text { Risk Management, Enterprise Risk Management, Integrated Risk } & 8 \\ & \text { Management and other variants } & 5 \\ \text { Chapter2 } & \text { Enterprise Risk Management: the intellectual and regulatory cases } & 15 \\ \text { Chapter3 } & \text { Integrated Risk Management: some arguments and implications } & 28 \\ \text { Chapter4 } & \text { Integrated Risk Management: some products and possibilities } & 39 \\ \text { Chapter5 } & \text { Enterprise Risk Management and Integrated Risk Management: some } & 46 \\ & \text { opinions } & \\ \text { Chapter6 } & \text { Conclusions and directions for further research } & 55 \\ \text { Appendix } & \text { Questionnaire } & 63 \\ \text { Glossary } & & 66 \\ \text { References } & & 73 \\ \text { Supplement } & \text { Completed questionnaires from respondents } & 80\end{array}$

Diagrams: $\quad$ Disaggregation of enterprise risks 25

Reconciliation of the standard models of finance and insurance $\quad 26$

An alternative matrix view of the insurative model 27

Illustrations of joining risks and extending risk periods 36,37

Comparison of conventional and multi-line programmes 38 


\section{Introduction}

'There are several definitions of Integrated Risk Management. This publication does not offer further definitions, because the focus is on the tools and techniques that are available to achieve Integrated Risk Management." (AIRMIC (1999), p.4)

The Corporate Treasurer of LucasVarity plc ("LucasVarity", a major UK based components supplier to the automotive and aerospace industries) had turned to the publication concerned precisely because he was looking for a generally accepted definition of Integrated Risk Management, preferably one that his Board of Directors would find easy to understand. Thus he admired the sentiment expressed, but was nonetheless disappointed.

During the period October 1997 to September 1999, the Treasury department of LucasVarity was approached by more than a dozen financial services organisations and consultants with products or proposals including some or all of the phrases 'total risk', 'holistic risk', 'enterprise risk', 'strategic risk', 'integrated risk', 'firm-wide risk', or similar. Approaches also occurred to the Group Financial Controller and the Finance Director, generally motivated by the impending publication of the Turnbull Guidelines for directors on the internal controls implications of the Combined Code. It was clear that a bandwagon was beginning to develop, but it was not clear who was on it or where it was going.

At least four things did seem clear. First, although the company operated a multilateral netting system for intra-group foreign currency payments, only part of the group's internal foreign currency flows (and therefore risks) were thereby off-set (as was confirmed by KPMG Treasury Consultants, in September 1997). Residual exposures (other than US dollar/sterling) were managed on an ad hoc basis that would need to be carefully reviewed no later than the time of the planned introduction of the euro in January 1999. Following the sale of a major subsidiary in January 1998 and movement from a net debt to a net cash position, interest rate exposure would also have to be reviewed.

Second, LucasVarity managed several financial risks on the assumption that there was no benefit to be gained by managing them together, when the correlation between them was clearly imperfect. At least one external adviser (Citibank, in October 1997) suggested that there were potential savings to be made in managing imperfectly correlated financial risks together, for example sterling 
interest rates and the US dollar/sterling exchange rates (to both of which the company was exposed). Also, there was a prima facie case for looking into the possible use of average rate currency options in connection with the company's long term US dollar/sterling exposure.

Third, in the area of insurable risks, there were beginning to be clear advantages in multi-line, multi-year programmes (Willis Corroon, September 1997 and J\&H Marsh McLennan, December 1997), of which the company had not so far taken advantage to any significant extent. These advantages usually involved some or all of: premium cost; certainty of future coverage; reduced negotiation/administration; and simplified (or at least reduced) documentation. In fact, when Directors' and Officers' Liability Insurance was reinstated by the company in early 1998, this was done on a multi-year basis.

Fourth, although the management of insurable and financial risks were both the responsibility of the Treasury department, the methodologies used for risk transfer/risk retention in each case were not well coordinated.

The really confusing thing was that each of Citibank, KPMG, Marsh and Willis, not to mention several others, used the words integrated risk management to describe their ideas or approach.

A series of major disposals and restructurings meant that the priorities for the LucasVarity Treasury department during 1998 were refinancing, cash management and a possible change of domicile from the UK to the US, rather than risk management, but by the end of 1998 these various aspects of a possibly integrated risk management approach had resurfaced as a priority. The plan Treasury decided initially to adopt was to invite half a dozen of its major advisers, or would-be advisers, to present their various concepts of integrated risk management at a one day conference in New York, to be hosted by the company in the spring of 1999 .

The best laid plans of mice and men gang aft agley, and no sooner had this decision been made than LucasVarity submitted to an agreed cash bid from TRW Inc. ("TRW", a major US based components supplier to the automotive and aerospace industries). This resulted in the dismantling of the LucasVarity Treasury department within the next few months and the integration of its operations within those of the TRW Treasury department. As it turned out, TRW had already made considerable progress in integrating the management of its insurance risks (using a version of Marsh's RiskFusion $_{(\mathrm{SM})}$ ), but had not yet been able to move on to the next logical stage of including financial risks. 
The next opportunity for the former Corporate Treasurer of LucasVarity to revisit the subject of enterprise and integrated risk management has occurred with this MSc dissertation. Meanwhile, the world has moved on and Turnbull has become a reality, bringing the concept of firm-wide risk management much more into the spotlight for all UK listed companies. A previously sparse literature has also been somewhat extended.

In an attempt to try to address some of the issues described above this dissertation will therefore adopt the following structure:

Chapter 1 The lack of a common vocabulary and other issues associated with the management of risk on a coordinated basis is discussed in an historical context. The relationship between risk management and regulation is also noted and certain working definitions are stated for enterprise risk management and integrated risk management.

Chapter 2 This comprises a review of the intellectual and regulatory cases for enterprise risk management and integrated risk management, together with a brief review of the place of insurance in corporate finance theory and possible developments in insurance linked securities in Asset-Liability Management.

Chapter 3 Here we provide examples of the savings likely to be obtainable from integrated risk products and address several issues, including: the relationship between integrated risk management and alternative risk transfer; likely providers of integrated risk products; and structural implications for companies managing risk on an integrated basis.

Chapter 4 A description is provided of some generic and proprietary products targeted at those companies seeking to manage risk on an integrated basis, along with brief descriptions of published uses of these and similar products.

Chapter 5 The implications of Turnbull and the extent to which integrated risk management is being practised/sold is addressed in a series of structured interviews with a group of sophisticated risk management practitioners and advisers.

Chapter 6 Summary of conclusions and some directions for further research. 


\section{Chapter 1}

Risk Management, Enterprise Risk Management, Integrated Risk Management and other variants

\section{Risk Management}

Harris-Jones, J. and Bergin, L. (1997) noted in their summary that a primary aim of their book had been to challenge the careless use of the words 'risk management', p.88. Regrettably, the attachment of an additional word or two before this phrase is often undertaken with even less care than the use of the phrase itself, resulting in a great deal of confusion among advisers and practitioners as to what is meant by Risk Management, Enterprise Risk Management and Integrated Risk Management, along with other variants.

We will not attempt to investigate exactly when the first contribution to the confusion arose and we must also remember that individual contributions to the current condition of obscurity have actually been made with the opposite objective in mind, i.e. greater clarity. There is no criticism, therefore, intended towards any of the authors cited in the following review and analysis. It will also be understood that words and their applications evolve. For example, what is reasonably clearly and generally understood today by the phrase 'operational risk' would not have been generally understood as such less than a decade ago and could, indeed, have meant something quite different. Even today phrases such as 'commercial risk' do not have a generally agreed meaning. In another decade's time, operational risk may mean something different again. Also, whatever general definitions we shall seek to impose, the common sense attached to the context needs to be kept in mind.

It is perhaps convenient to continue with a brief review of the definition of 'risk management' itself. According to Kloman, H. F. (1990), the term first appeared in print in the Harvard Business Review in an article by Russell Gallagher in 1956, although it had been in conversational use for some years before. Mehr, R. I. and Hedges, B. A. (1963) in one of the earliest texts on the subject considered it to be the management of those risks for which the organisation, principles and techniques appropriate to insurance management were useful. This did not satisfy Bannister, J. E. and Bawcutt, P. A. (1981), p.5, who stated "Sixteen years later that definition looks unreasonably narrow", pointing out that the separation of insurance from other risks was both impractical and 
undesirable. They believed that risk management may be defined as the identification, measurement, and economic [their emphasis] control of risks that threaten the assets and earnings of a business or enterprise. Their framework for the analysis of risk comprised nine categories: property, business interruption, liability, social, political, environmental, technological, wastage and management error.

Almost contemporarily, Crockford, N. (1980), p.4 believed "There is nothing very complicated about risk management", but his own definition was not terribly helpful: "Risk management seeks to apply known methods of dealing with the problems of risk in a more effective and more ordered form and to devise new or improved methods of minimising or financing loss". However, he recognised that barriers between the management of pure and speculative risks were artificial and proposed a risk framework with seven dimensions: property, accident, political and social, technical, marketing, labour and liability. Crockford also introduced the concept of a 'silo mentality' with respect to risk, which was revisited by later authors.

Doherty, N. A. (1985), p.1, conceded that 'The term risk management does not yield to simple definition", with which others still agreed more than a decade later, e.g. "The term risk management does not have a universally agreed definition", Goldman Sachs and SBC Warburg Dillon Reed (1998), p.29. Doherty also provided a classification of risks that he perceived as aggregating to the risk of the firm as a whole: marketing risk, financial risk, resource management risk and environmental risk. He appears to have been able to resist the temptation to describe his approach as anything other than simple risk management, but by implication this is one of the earlier references to firm-wide risk.

The debate has continued in print and elsewhere and even the later definition of Kloman, H. F. (1992), p.305 "Risk management is a discipline for living with the possibility that future events may cause harm" did little to help in a practical sense. This state of terminological confusion has continued to be recognised recently by Kloman, H. F. (2000).

Risk Management: is it even a separate discipline?

Chris Parsons of the City University Business School has raised the question of whether a 'profession' that cannot even really define what it does deserves to be treated as a separate discipline (private communication, $16^{\text {th }}$ June 2000 ) or is merely a passing management fad. An academic 
response to this question is outside the scope of this dissertation, but some indication may be gleaned by considering the answers to a number of test questions, as follows:

(1) Have practitioners formed themselves into 'professional' bodies in one or more countries, with at least some categories of membership based on entry by examination?

(2) Do organisations commonly employ people with a title involving the name of the 'profession'?

(3) Do recruitment advertisements appear under the name of the 'profession'?

(4) Are postgraduate or undergraduate courses taught in the subject?

(5) Has the 'profession' generated a vocabulary increasingly unintelligible to outsiders?

(6) Has there been at least one major conference in an expensive location devoted to the subject for at least ten years?

It will be observed that the answer to each of these questions is yes, so that there does appear to be a prima facie case for treating risk management as at least a nascent profession and a discipline in its own right.

\section{Enterprise and Integrated Risk Management}

As we have seen above, some of the earliest arguments in favour of a coordinated approach to risk management began to be voiced in the 1980's. However, it was not until fairly late in that decade and into the 1990's that the debate of how to describe the coordinated approach to risk management began in earnest.

Haimes, Y. Y. (1989, 1991 and 1992) uses both the terms 'total risk management' and 'holistic risk management'. He defines total risk management as a systematic, statistically based and holistic process that builds on formal risk assessment and management and addresses the sources of failures within a hierarchical-multiobjective framework. In the context of his work, 'holistic' has its conventional meaning of applying to the system of risks as a whole, rather than to individual risks, in the course of which he acknowledges the work of Bayes, Russell and other mathematicians who had contributed to this area. Moreover, his analysis goes beyond a simple recognition that certain risks would inevitably be related to encompass the fact that resources for dealing with such risks would be finite.

Strutt, R. S. G. et al (1991) notes that risk management is becoming more holistic ${ }^{1}$ and this view

\footnotetext{
${ }^{1}$ In fact, Strutt's paper contains a valuable review of the debate on the limits of risk management.
} 
was echoed by Kloman, H. F. (1992), p.306 "It [risk management] should be a holistic endeavour, one that looks at all risks and their inter-relationships including primary, secondary and tertiary effects." Strutt also argues that the typical purview of risk managers and treasurers is too compartmentalised and that their time-frames are usually too short. Kloman uses a somewhat different framework to that suggested by Doherty described earlier, in this case the risk components being: financial/market, operational, political and legal. Kloman also toys with the concept of coherent risk management, as opposed to 'balkanized' or fragmented risk management.

Dickinson, G. M. (1994) provides a comprehensive review of the evolution of risk management and notes that the origins of strategic risk management are traceable to contingency planning models. This paper contains an important summary of the theoretical justification for an integrated approach to risk management, which will be dealt with in more detail in Chapters 2 and 3. Meanwhile, it should be noted that Dickinson's references to 'operational' risk are more akin to what we are now beginning to recognise as 'enterprise' risk in more recent work.

Dehnad, K. (1996) concentrates on the interaction of financial risks and provides a framework for analysing the over-hedging likely to result from failing to integrate financial hedging decisions. His useful analogy of relating combinations of hedges to the dangers of mixing medical prescriptions without careful thought is one that many treasurers should remember.

The work of Ross, D. A. (1997) is addressed specifically at financial institutions and provides a framework whereby Value-at-Risk ("VAR") techniques are applied to all the risks of such an institution (i.e. insurable as well as financial), which is his definition of strategic risk management. He also points out that such techniques are ideally suited for institutions subject to regulation under the Basle Committee on Banking Regulation and are also of relevance to any organisation where the stability of its credit ratings are critical. Another example he could have chosen would have been insurance companies regulated under one of the Risk Based Capital ("RBC") régimes, for example Canada or any one of the United States of America. The proposed changes to the regulatory system in use for insurance companies within the European Community may also increase the relevance of this view in the future.

Harris-Jones, J. and Bergin, L. (1997), whose work was noted at the beginning of this Chapter, attempt to provide a comprehensive framework for integrated risk management. The introduction to their book was written by Christopher Tugendhart (Chairman, Abbey National plc), who observed, p.3, that while the Cadbury Report emphasised only the need for controlled financial risk, 
the Hampel Report focused attention on business risk assessment and response. The influence of regulation on risk management is examined in detail in Chapter 2.

Sanderson, S. M. (1997) points out that there are some obvious reasons why financial and insurable risk management are often not well coordinated, even when both come under the responsibility of a single department (usually Treasury). One is that it is often very straightforward to hedge financial risks on an individual basis and at 'no cost', in the sense that no premium will be payable if a derivative such as a forward contract is used. The default decision is often to hedge financial exposures rather than to leave them exposed, frequently with a low de minimus limit. Insurable risks, conversely, are seldom dealt with on an individual basis and are usually subject to intense analysis, including explicitly examining the balance between risk retention and risk transfer; for large companies a high degree of risk retention is commonplace. This difference is not simply philosophical, it is related to the fact that financial risks are two-way and insurable risks one-way. It may also be noted that the accounting and tax treatment of insurance and hedging products can be very different.

Berry, A. and Phillips, J. (1998) recognise the profusion of terms used in connection with coordinated risk management and provide a definition for enterprise risk management, being the consistent application of techniques to manage the uncertainties surrounding the achievement of an organisation's objectives. They continue by providing a list of key propositions in connection with this approach, most of which would be readily recognised by anyone familiar with the work of Dickinson (op. cit.) The same could be said of the strategic risk management approach recommended by Rahardjo, K. and Dowling, M. A. (1998), which recognises the inter-relationship between objectives, strategy and risk management. They also point out that a strong framework of internal controls needs to be established and the firm's risk management information system integrated with other company-wide networks.

It may be appropriate to make a short detour here to consider some of the proprietary systems available for enterprise risk management. Many of these products synthesise techniques that have been used individually before, for example scenario analysis and Monte Carlo simulations, which is not to say they are not sophisticated developments in their own right. Examples may be found in Davies P. and Reichenberg, E. (1998), describing Askari's RiskBook ${ }^{\text {TM }}$ and Hiscock, J. (1999), describing BARRA's TotalRisk ${ }^{\mathrm{TM}}$.

AIRMIC (1999) firmly favours the use of the phrase 'integrated' risk management, whilst 
conceding that it could also be described as 'all-risks' or 'holistic'. Their references to the boost the subject has received following the publication of the Combined Code unfortunately bring to mind thoughts of emperors and new clothes, while the purported benefits of integrated risk management exceed only those of snake-oil. The recommendation of an appointment to Chief Risk Officer at main board level is hardly surprising, but likely to be no more convincing or practical in most companies than similar level appointments for Chief Information Officer, Chief Marketing Officer or whatever other professional body happens to be making the recommendation.

Merton, R. C. (1999) addresses the general principle of integrated risk management and specifically addresses, among other institutions, the non-financial firm: "Indeed, taking into account risks on both sides of the balance sheet is fundamental to providing effective financial services to non-financial firms in general. Enterprise risk management is one term for such a unified approach. "He also argues that from individuals to entire nations, the future of financial services lies with integrated products that are more comprehensive, simpler to understand and more reliable for the user.

It is tempting to allow the words of a Nobel Laureate to close this Chapter, but it will first be necessary to at least agree on a terminology that can be applied consistently throughout the following pages. We do this with some trepidation, but in the knowledge that its failure to be generally accepted will be no worse than the fate of other attempts before.

Financial risks Those risks, usually arising through economic causes, that can be nullified by entering into a derivatives contract designed to produce an equal, but opposite, result (i.e. hedged). To the extent that the correlation between the risk and the derivative is imperfect, the loss may not be fully indemnified. These are also known as speculative, or dynamic, or 'two-way' risks, since they can result in gains or losses. Although some derivatives involve the payment of a premium (e.g. currency options and interest rate caps), others do not (e.g. forward foreign exchange contracts and interest rate swaps).

Insurable risks Those risks, usually arising through natural causes or human accident or error, that can be transferred to third parties through the use of traditional insurance contracts (i.e. insured). The loss will be fully indemnified, within agreed coverage limits, in the event of a bona fide claim. These are also known as pure, or static, or 'one-way' risks, since they can only result in losses. Conventional insurance policies always involve the payment of a premium. 
Integrated risk management The management of financial and/or insurable risks on an integrated basis, i.e. taking into account their degree of interdependence. Unlike Enterprise risk management (see below), it is about specific techniques and tools used for this purpose.

Operational risks Those risks that cannot be hedged or insured. They are also generally speculative, in the sense that like financial risks they can result in gains or losses. It is to be expected that over time the relative number of such risks will reduce as additional derivatives and insurance products are developed, a recent example being patent risks, for which see Shimpi, P. A. (1999), p.82.

Enterprise risks The sum of the financial, insurable and operational risks facing an enterprise.

Enterprise risk management The management of all the risks facing an enterprise on a comprehensive and holistic basis, taking into account their inter-relationships and the resources available for their management. It is therefore an approach to, or a philosophy for, risk management, rather than a particular technique or series of techniques. (Further justification for this definition will be given in Chapter 2.) In its very widest sense it may also include the allocation of capital within a corporation and the use of tools designed to facilitate risk management.

If the phrases Strategic or Firm-wide risks or Strategic or Firm-wide risk management are used, they will have the same meaning as Enterprise risks and Enterprise risk management respectively.

There are many aspects of risk management that will not be dealt with at all in this dissertation, for example the concept of the total cost of risk and the standard analytical framework of: identification and measurement/avoidance and reduction/retention and transfer; these are not new and covered quite adequately in many standard texts, such as Crockford, N. (1991) and Gordon, A. (1992). 


\section{Chapter 2}

\section{Enterprise Risk Management: the intellectual and regulatory cases}

\section{Introduction}

In this Chapter we shall examine the intellectual and regulatory cases for enterprise risk management. We shall also address the place of insurance in corporate finance theory and, finally, the relationship between integrated risk management and asset-liability management through the medium of insurance-linked securities.

\section{The Intellectual Case}

Economic theory teaches us that when a firm or other organisation has a number of different policy instruments at its disposal, the most efficient combination to achieve any given goal is the one for which: (a) the incremental benefit of any instrument is the same; and (b) the last pound spent on each instrument provides a pound of benefits in return. In other words, the marginal benefit must just equal the marginal cost ${ }^{2}$. When the goal is risk reduction and the policy instruments include insurance policies and derivatives, it should be clear that we need to consider all of these together, but there is an even more fundamental level at which it is convenient to begin our analysis.

Dickinson, G. M. (1994) provides an important discussion of the intellectual basis for a more integrated approach to risk management, which we summarise here. His starting point is that any category of risk is intimately related to the strategy of the firm. The examples he offers are property risks being the almost invariable result of a decision to control productive capacity and currency risk being the natural consequence of international operations. One could similarly consider interest rate risk following from the decision to borrow and credit risk from the decision to sell on an other than cash basis. Each of these four examples, however, shares the characteristic that they can be insured or hedged. The third category, of operational risks, for example the risk of a workforce going on strike or of a technology being more costly to develop than anticipated (e.g.

\footnotetext{
${ }^{2}$ This point is expanded upon in Shimpi, P. A. (1999), Chapter 2 (The Conventional Approach to Risk Management, contributed by David S. Laster).
} 
the RB211), cannot be hedged or insured. Dickinson goes further in arguing that it is only the existence of hedging or insurance products that serves to disaggregate financial and insurable risks from the total risks facing an enterprise and that the development and extension of derivatives and insurance products means that over time a risk may cease to be operational and become financial or insurable.

A corollary to this argument is that risk management must be an integral part of the strategic management process. There needs to be a logical progression from the corporate mission statement, through corporate objectives to corporate strategy and then an evaluation of strategy outcomes, including the risk of objectives not being achieved. If risks inherent in the strategy cannot be managed to an acceptable level given the available tools, then the strategy needs to be modified, leading to an iterative process. We will return to the implications of this and appropriate risk and return measures below.

His second observation is that whatever measure is adopted, risk is not additive. Other than under very restricted circumstances the risk of a system taken as a whole is not the sum of the risks of the parts; this is the principle of diversification arrived at through the law of large numbers (or stated more rigorously, the larger a sample, the nearer its mean is to that of the parent population from which the sample is drawn). It is only possible to go from the risks of the components of a system to the risk of the system as a whole, or vice versa, if we have knowledge of the statistical interdependency between the risks of the components.

We now need to address the questions of what constitute appropriate measures of return and risk. It is clear that there is considerable freedom of choice available. For many enterprises the objectives will be summarised in one or more financial goals, an example of which might be that the company should consistently achieve an overall return in excess of its cost of capital, or more specifically, from the perspective of its shareholders, an equity return above its cost of equity. If this is indeed the case, then an appropriate and consistent measure of enterprise risk might be the variation of return on equity about its estimated cost of equity.

We may therefore represent the enterprise risk of the firm graphically in terms of the dispersion of the return on equity, which will typically have an approximately normal distribution. Illustrative distributions are reproduced immediately after this Chapter (page 24). In line with our preceding arguments, a mean in excess of the cost of equity is a necessary, but not sufficient, condition for an acceptable strategy. It is also possible to draw some conclusions concerning the likely shape of the 
distributions of the three categories of constituent risk and we again follow Dickinson.

Financial risks. If we assume that all financial markets are efficient, the distribution of financial risks will also be approximately normal, but with a mean of zero and a smaller standard deviation than that of the aggregate distribution.

Insurable risks. The distribution of insurable risks will have an upper bound of zero and a mean of somewhat less than zero; it will be skewed towards the right.

Operational risks. We arrive at a distribution for operational risks by disaggregating the financial and insurable risks from the overall distribution, bearing in mind the limitations on our ability to do this discussed above. The elimination of financial risks from the aggregate distribution will have the effect of reducing the variance, but leaving the mean unchanged. The elimination of the insurable risks will have the effect of increasing the mean (since insurable risks can only have negative outcomes), reducing the variance and skewing the distribution towards the left (i.e. in the opposite direction to the skewness of the distribution of insurable risks).

Ignoring costs, the effect of removing financial and insurable risks is, therefore, to increase the expected return and reduce the variability of returns, but of course we cannot ignore costs. The elimination of financial risks will have limited costs to the extent that non-premium products are utilised (e.g. forwards and swaps), but the use of options and similar products could involve significant premiums. The elimination of insurable risks will involve premiums. Thus although the shape of the operational risks distribution remains as we have deduced it, it is shifted bodily towards the left. It will be clear that if the mean of this distribution does not exceed the company's cost of equity, the strategy will not be acceptable.

What we have looked at in the foregoing paragraphs has been an extreme example. In principle we can remove any combination of financial and or insurable risks and view the result in terms of the expected return and the expected variation in return. By doing this for a large number of scenarios we can construct an efficient frontier and either choose the minimum level of risk for a given return or a maximum return for a given level of risk. This is exactly analogous to the selection of efficient portfolios in asset management. 
The Regulatory Case

In the United Kingdom the regulatory case for managing risks on a coordinated basis has its genesis in a series of reports on corporate governance that commenced in the early 1990's. It would be attractive to be able to state that the case for enhanced corporate governance rested upon a recognition of the added value that increased risk awareness could bring, but in reality it is more likely to have been a series of scandals that began in the 1980's and continued into the 1990's: Johnson Matthey Bank, Barlow Clowes, Polly Peck, BCCI, Maxwell and Barings. There were also other factors, such as a continuing controversy over the remuneration packages of company directors.

The first committee to be set up, in 1991, was under the Chairmanship of Sir Adrian Cadbury; its sponsors were the Financial Reporting Council, the London Stock Exchange and the Consultative Committee of Accountancy Bodies. It published an interim report in May 1992 and, after a period of consultancy, its final report in December of that year. Its title was the "Report of the Committee on Financial Aspects of Corporate Governance", known as the Cadbury Report, and it included a code of best practice dealing with the structure and responsibilities of boards of directors, the role of auditors and the rights and responsibilities of shareholders. Despite its focus on financial issues, it did make one recommendation concerning risk management "Boards should have a formal schedule of matters specifically reserved to them ... including risk management policies".

The second committee to be set up, in 1993, was under the chairmanship of Sir Richard Greenbury; it was sponsored by the government. It published its final report in July 1995 under the title "Report of the Study Group on Directors' Remuneration", known as the Greenbury Report. Its code of best practice dealt with the need for board remuneration committees, reports to shareholders and service contracts and compensation. It had little to do with risk specifically, but did lead on to a third committee of more direct relevance.

The Cadbury and Greenbury committees recommended that a new committee should be set up to review the implementation of their findings. The new committee was thus established in November 1995, under the chairmanship of Sir Ronald Hampel, on the initiative of the Financial Reporting Council. The sponsors of the committee were: the London Stock Exchange, the Confederation of British Industry, the Institute of Directors, the Consultative Committee of Accountancy Bodies, the National Association of Pension Funds and the Association of British Insurers. It published an interim report in August 1996 and, after a period of consultancy, its final 
report in January 1998. Its title was the "Report of the Committee on Corporate Governance", known as the Hampel Report. Among the principles espoused by the committee was that "The board should maintain a sound system of internal control to safeguard shareholders 'investment and the company's assets. This covers not only financial controls but operational and compliance controls, and risk management, since there are potential threats to shareholders' investment in each of these areas" (p.21). Another of Hampel's recommendations was that the principles established in the Cadbury, Greenbury and Hampel Reports should be gathered together in a "Combined Code" and that guidance notes should be prepared to expand upon what is meant by "Internal Controls".

The Combined Code was published in June 1998 and provided comprehensive detail on principles of good governance, the role of the board and of shareholders, directors' remuneration, accountability and audit and the public reporting of risk. The Combined Code reiterated the principle of sound internal control contained in the Hampel Report.

The preparation of the guidance notes recommended by the Hampel Report was delegated to the Internal Control Working Party of the Institute of Chartered Accountants in England and Wales ("ICAEW"), under the chairmanship of Sir Nigel Turnbull. "Internal Control: Guidance for Directors on the Combined Code" was published in September 1999, and is usually known as the Turnbull Guidelines. The Turnbull Guidelines contain a further reiteration of the Hampel/Combined Code principle referred to above. Although they adopt an audit/internal control approach rather than the risk management approach some had hoped for, there are several references to risk and risk management.

'The guidance is based on the adoption by a company's board of a risk-based approach to establishing a sound system of internal control and reviewing its effectiveness. "(p.4, §9)

"A company's system of internal control has a key role in the management of risks that are significant to the fulfilment of its business objectives. ”(p.4, §10)

"A company's objectives, its internal organisation and the environment in which it operates are continually changing. A sound system of internal control therefore depends on a thorough and regular evaluation of the nature and extent of the risks to which the company is exposed. Since profits are, in part, the reward for successful risk-taking in business, the purpose of internal control is to help manage and control risk appropriately rather than to eliminate it. "(p.5, §13) 
"In determining its policies with regard to internal control, and thereby assessing what constitutes a sound system of internal control in the particular circumstances of the company, the board's deliberations should include consideration of the following factors:

- the nature and extent of the risks facing the company

- the extent and categories of risk which it regards as acceptable for the company to bear

- the likelihood of the risks concerned materialising

- the company's ability to reduce the incidence and impact on the business of risks that do materialise; and

- the costs of operating particular controls relative to the benefit thereby obtained in managing the related risks.” (p.6, §17)

"When reviewing reports during the year, the board should:

- consider what are the significant risks and assess how they have been identified, evaluated and managed

- assess the effectiveness of the related system of internal control in managing the significant risks, having regard, in particular, to any significant failings or weaknesses in internal control that have been reported ...” (p.9, §31)

Listed companies must implement the guidelines for financial years ending after $23^{\text {rd }}$ December 2000 and many will be forced by their advisers to confront issues relating to business risks that they may previously have been content to ignore.

It would be wrong to assume that this is entirely a UK trend. Kloman, H. F. (2000) has pointed out the relevance of the Treadway Commission in the US and the Dey Committee ${ }^{3}$ in Canada, while Raschewski, T. (1999) notes the new German KonTraG Law (Control and Transparency in Entities). Banham, R. (1999) relates the UGG deal described in Chapter 4 directly to the then new Toronto Stock Exchange corporate governance guidelines requiring boards of directors to understand all the major risks faced by a company and to approve plans for dealing with those risks.

\footnotetext{
${ }^{3}$ The report of the original Dey Committee led to the publication of the Toronto Stock Exchange ("TSE") guidelines on corporate governance in 1994. The TSE reconvened the committee this year (2000), six years after it originally reported, to review the changes that had taken place during that time, which were regarded as mainly positive, although with a sense that the momentum of change for the better was now decreasing.
} 


\section{Insurance and Corporate Finance Theory}

Before addressing the place of insurance in corporate finance, we must briefly review the economic rationale for insurance. From the point of view of a portfolio investor, it has been pointed out by Doherty, N. A. and Smith, C. W. (1994) and others that insurance does not necessarily bring any benefit to the market portfolio, where both the company buying the insurance and the company selling the insurance are constituents of the portfolio. The fact that profit is transferred from one organisation to another is not critical, but costs associated with that transfer are avoidable. The result is that, on average, a pound spent on premiums will result in less than a pound returned in claims, a phenomenon sometimes referred to a 'friction'. There is thus a strong economic case for the retention of risk where this does not jeopardise the financial stability of the firm ${ }^{4}$. The reason for this caveat, briefly, is that there are very real costs associated with financial distress, both in terms of actual additional costs incurred (e.g. through suffering worse terms with suppliers of credit than would otherwise be the case) and of projects foregone through unavailability of capital (i.e. opportunity costs). We should note that this argument applies not only to conventional insurance, but also to other products having a similar result, for example financial derivatives used for purposes of hedging.

Since the risks faced by a firm will be distributed according to some statistical distribution, it is not possible to postulate even theoretically a single optimal level of capital that should be held by a firm to engage in a given range of business activities. However, this can be done if a particular confidence level is selected, say $95 \%$ or $99 \%$. The greater the level of confidence the higher the level of capital required, which implies that the additional capital is in some way in excess of operating requirements and held only as a form of internal insurance, a deduction supported by theoretical arguments. The question then arises as to whether, at a given confidence level, this capital should be the same for two otherwise identical firms, one of which insures and/or hedges certain of its risks and one of which does not. Intuitively the answer must be no, with the insurance purchased serving to reduce the amount of 'excess' capital required. In other words, to retain the same level of protection against insolvency, a company without insurance for major risks will need to hold more capital than one with such insurance. Due to the presence of the frictional losses described above, however, the reduction in capital will generally be less than the amount of insurance purchased.

\footnotetext{
${ }^{4}$ This point is examined in Shimpi, P. A. (1999), Chapter 1 (Everyone is a Risk Manager, contributed by David S. Laster).
} 
This point is almost entirely absent from most reference works on corporate finance and it is recognised in none of the standard models. For example, the presence or absence of a comprehensive insurance programme would not generally be recognised in the calculation of a company's Weighted Average Cost of Capital ('WACC'), although it will clearly have implications for the level and stability of future cash flows. One of the few authors to attempt a reconciliation of the standard models of insurance and finance is Shimpi, P. A. (1999), Chapter 3.

The diagrams used by Shimpi to illustrate this reconciliation are reproduced after this Chapter (page 25). We may start from either the Standard Finance Model or the Standard Insurance Model. In the former, the capital of a company is viewed only in the narrow sense of 'on-balance sheet capital', usually in terms of horizontal layers ranging from equity (most risky) through various forms of mezzanine finance to senior debt (least risky). In the latter, risk is viewed as simply being retained or transferred, usually in vertical 'towers'. The insurative model both combines these two views and extends them by maintaining the retained and transferred divisions of risk and introducing the concept of on-balance sheet and off-balance sheet capital. It will be seen from these that Shimpi's model also permits the explicit recognition of true contingent capital and insurance linked capital, which do not fall naturally into either of the two progenitor models. A perhaps more convenient method of visualising these divisions, also given after this Chapter (page 26), is by means of a matrix, where the horizontal axis is divided between on-balance sheet and off-balance sheet capital and the vertical axis is divided between risks retained and risks transferred.

The analytical insurative model developed by Shimpi explicitly takes into account the reduction in capital associated with any insurance programme and factors the cost of such a programme into a company's Total Average Cost of Capital ('TACC'). By this means it is possible to see whether a given programme increases or decreases a company's TACC and thus to estimate the impact on more conventional financial measures, such as Return on Equity ('ROE'). Space does not permit the review of these important issues in depth, but it is appropriate to consider in more detail a particular aspect of one of the classes of capital incorporated within Shimpi's model and this we now do. It may be noted that the principal features of 'conventional' contingent capital (e.g. Aon's CatEPut ${ }^{\circledR}$ structure) and 'conventional' insurance linked securities (e.g. various examples of catastrophe bonds) have been dealt with quite adequately in the existing literature, for example Ash, J. et al (1999) and Shimpi, P. A. (1999) respectively. 
Integrated Risk Management and Asset-Liability Management

Up to this point we have used the word 'integrated' to refer only to the joint management of insurable and financial risks. However, it is also possible to use the word in a quite different way. Asset-Liability Management is most frequently encountered in connection with financial institutions and is generally taken to mean the coordinated management of assets and liabilities so as to leave the value of the firm largely unchanged in the event of unexpected movements in financial variables (e.g. foreign exchange rates, interest rates, share prices, commodity prices, etc.). This is achieved by the use of a wide variety of techniques that are well described in standard texts, e.g. Gardner, M. J. and Mills, D. L. (1994). A more direct form of integration between asset and liability management can occur when the return on a liability is tied directly to the return on an asset, e.g., albeit imperfectly, in the case of an oil bond (see Hull, J. C. (2000)). However, as has been pointed out by Professor Gerry Dickinson of the City University Business School (private communication, $12^{\text {th }}$ July 2000), such a direct form of integration could also be constructed in both financial and non-financial institutions by relating the return on a liability at least in part to an insurable event (e.g. property losses) rather than to a financial event (e.g. interest rates). In a limited form this has already happened.

The convergence of insurance and capital markets has been epitomised by the successful introduction of catastrophe bonds over the last few years ${ }^{5}$. Although the structure of such issues varies, they almost invariably involve a Special Purpose Vehicle (for tax reasons) and the investment of all or part of the proceeds in highly liquid and secure investments that can be called upon only on the occurrence of a specified event. The equivalent 'premium cost' is readily calculated as the difference between the risk free rate and the actual interest cost, together with any associated expenses. However, since the issuer does not have the use of the money, there is a carrying cost relative either to the company's marginal cost of debt or marginal cost of capital, depending on its perspective.

\footnotetext{
5 See, for example, The Economist ("Disaster Relief", July 29, 2000), “... the best example of the convergence between insurance and the capital markets".
} 
The problem of carry cost would be obviated if the funds were freely available for use by the company. This implies that the bonds might be general corporate obligations of the borrower, but with the repayment of all or part of the principal and/or interest linked to one or more insurable events. A further consequence is that the credit rating and pricing of the bond would have to reflect the specific event risk as well as other risks normally priced into bonds. The result could come close to the criteria for a form of ideal insurance, that is: (1) low cost (once issued, the administrative costs associated with the bond will be minimal); (2) multi-year; (3) secure (debt non-repayment is effectively equivalent to a risk free cash inflow from the perspective of the issuer); (4) in a form familiar to capital markets investors (i.e. bonds); and (5) involving as high a level of risk retention as the issuer desired. Whilst true just-in-time or kanban capital might have even greater theoretical economic advantages and prove superior in the long term, this variant might well become popular in the medium term as the inherent disadvantages of catastrophe bonds as presently structured become more apparent. 


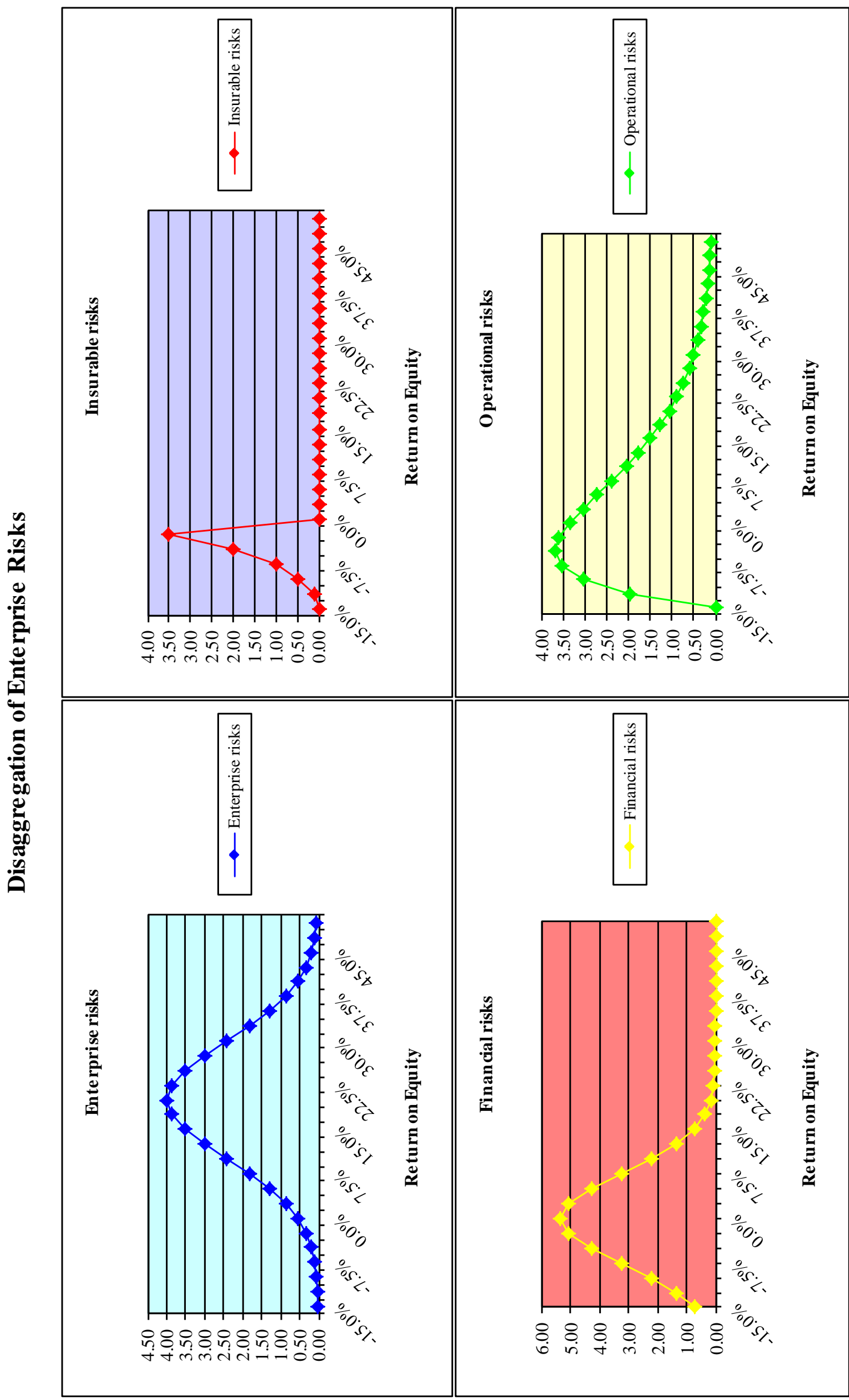

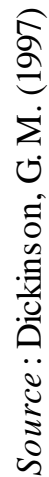




\section{Reconciliation of the Standard Models of Finance and Ins urance}

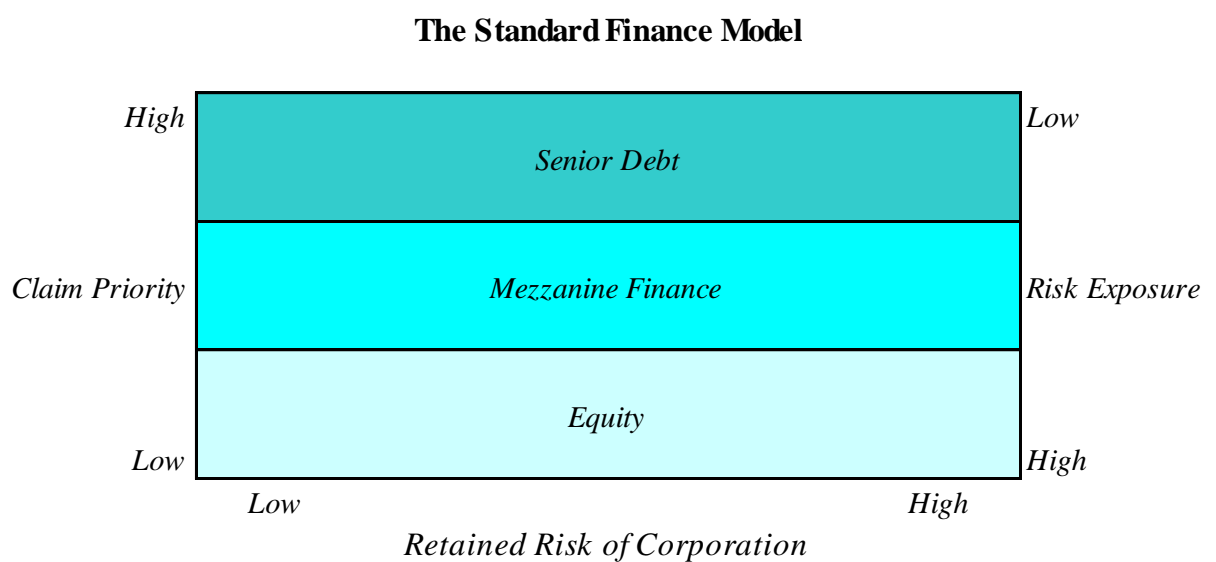

The Standard Insurance Model

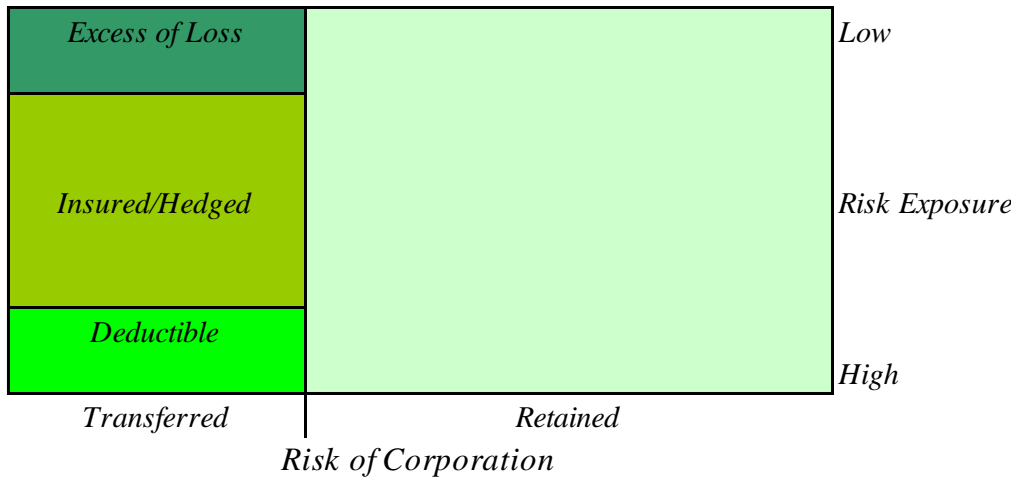

The Insurative Model

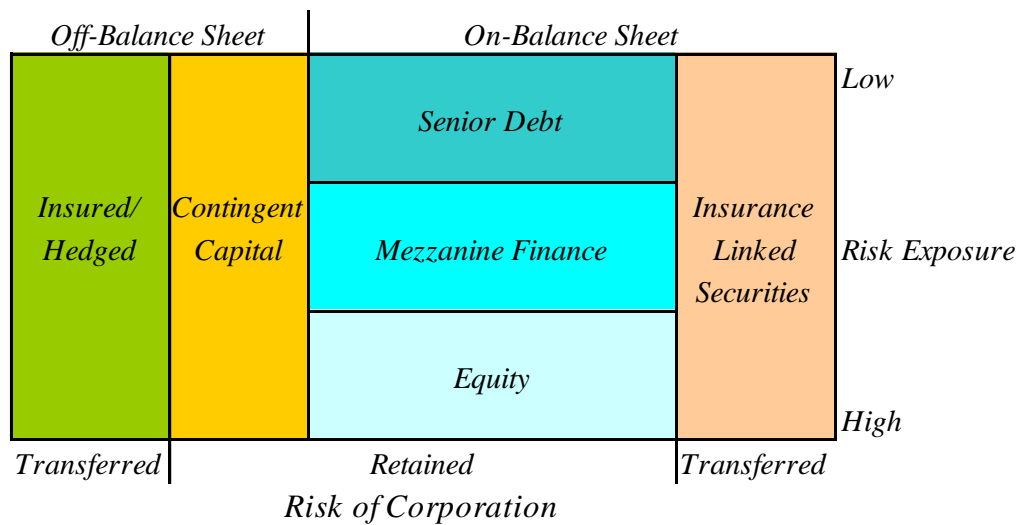

Source: P. A. Shimpi, Integrating Corporate Risk Management, Swiss Re New Markets, 1999. 


\section{An Alternative Matrix View of the Insurative Model}

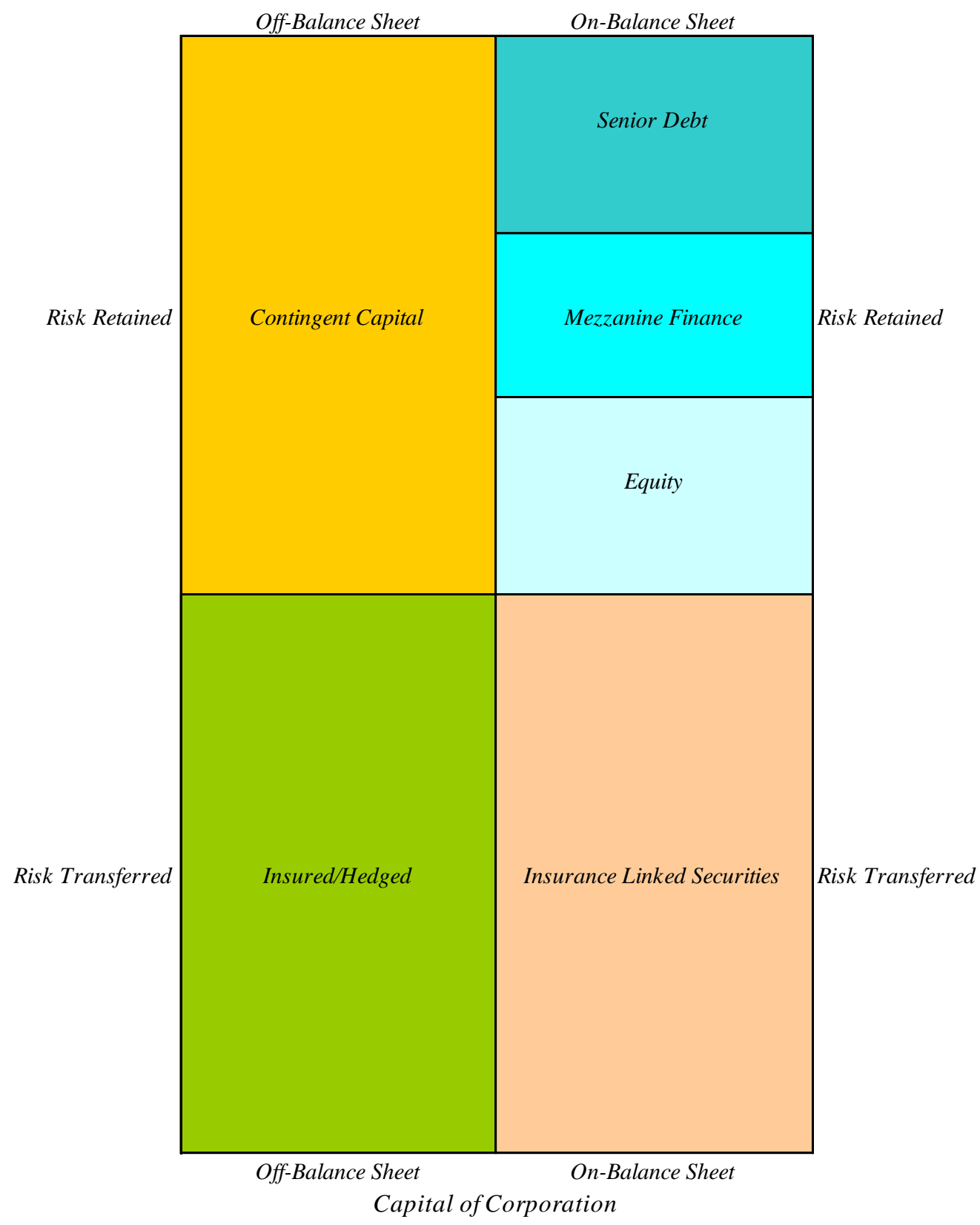

- In principle, the cost of capital of a company should take into account all capital, regardless of whether it is on or off the balance sheet and whether or not it is used to transfer risk to a third party. 


\section{Chapter 3}

\section{Integrated Risk Management: some arguments and implications}

Empirical Advantages of Multi-year, Multi-line Products

Three idealised examples of the benefits of integrated risk management appear in Sanderson, S. M. (1997), one of which was also quoted in Forbes Magazine ("Who needs derivatives", April 21, 1997). We present slightly modified versions of these examples below, with the kind permission of the author. Graphical representations of the various cases appear immediately after this Chapter (pages 35 and 36); in each case sterling values are shown alongside US dollar values.

Single year - joint risks (insurable and financial)

Consider first the workers compensation exposure of a large, well-managed US industrial company with annual expected losses of GBP 7.5 million, all US related, and the currency exposure arising from a forecast year-end dividend from its German subsidiary of DEM 150 million. Statistical modelling of each risk independently using straightforward simulation methods might result in the conclusion when they are added that there is a $90 \%$ probability that the annual loss cost will not exceed GBP 15.2 million on a combined basis.

However, the two exposures are not additive for the reasons explained in Chapter 2. Since the exposures are not occurring in isolation, a flatter distribution will result from modelling the losses on a joint basis, leading to the conclusion that there is, in fact, a $90 \%$ probability that the annual loss will not exceed GBP 13.4 million. The reduction in the 90\% probability loss level of GBP 1.8 million (i.e. from GBP 15.2 million to GBP 13.4 million) is typical of such examples and quite intuitive, since favourable results in one risk can offset unfavourable results in the other.

We should note that the expected loss is the same in each case, so that this is the point of intersection of the two loss curves (i.e. at the $50 \%$ probability level). This is also true of the following two examples. 
Five years - single risk (insurable)

We next consider an individual risk over a period of time longer than that which normally applies. For example, workers compensation is normally insured on a single year basis. We may compare the combined $90 \%$ probability that the annual loss over five years will not exceed GBP 51.2 million (i.e. five times the single year $90 \%$ loss level) with the joint $90 \%$ probability of aggregate losses over five years not exceeding GBP 44.9 million, a reduction of GBP 6.3 million (i.e. equivalent to GBP 1.3 million per annum). The same flattening effect occurs as when combining exposures and this is again intuitive, since here favourable results in one year can offset unfavourable results in another. Although we shall not consider the figures in detail, the same behaviour would be encountered if we examined the behaviour of the currency exposure over five years.

\section{Five years - joint risks (insurable and financial)}

Given the foregoing, it will come as no surprise that the effect of both joining risks and lengthening the time horizon results in an even more dramatic reduction in joint probability. Combining five year independently modelled workers compensation and currency exposure losses leads to an expected loss at the 90\% level of GBP 75.9 million, whereas when jointly modelled the aggregate loss at the $90 \%$ level is GBP 51.9 million, a reduction of GBP 38.5 million (i.e. equivalent to GBP 7.7 million per annum).

These examples are in no sense special, similar results would be obtained in any circumstances where a portfolio effect is introduced or the time horizon is lengthened. However, they do not represent a free lunch. For the enterprise to benefit requires it to take a different perspective to that which it has done before, that is to view loss levels in aggregate rather than individually and over a longer time horizon. Another potential problem is the difference in the tax and accounting treatment applied to traditional insurance, financial derivatives and integrated products.

\section{Practical implications}

If we continue with the data underlying the foregoing examples, realistic premium levels for the two separate programmes might be USD 15.0 million $^{6}$ for the workers compensation (mean loss USD 12.0 million) and USD 3.5 million for the currency exposure (assuming a twelve month, at the

${ }^{6}$ In practice there might well be some experience pricing (i.e. profit sharing) adjustment, but we shall ignore this for the purpose of our example since it might also apply to the alternative product we shall consider. 
money forward DEM put/USD call option covering the whole of the downside risk). Since the expected loss on the currency exposure is zero, another way to look at this is that the company would be willing to pay USD 6.5 million per annum to cover negative outcomes for the two risks. Traditionally each might represent good value viewed separately, but do they represent good value viewed together?

One way to answer this question would be to price a product that provided protection for an aggregate of losses on workers compensation and currency exposure in excess of USD 12 million; an example of such a product would be a single year version of Marsh's Risk Fusion ${ }_{(\mathrm{SM})}$, for details of which see Chapter 4. Using consistent pricing methods the premium for such a product would be of the order of USD 1.7 million. This means that the expected loss/premium combination in any year would be USD 13.7 million, or USD 4.8 million lower than the expected loss/premium combination in our previous example. $50 \%$ of the time the whole of this differential will be captured, while in other years the net advantage against the traditional approach will be between zero and USD 4.8 million, depending on the actual level of losses. While the volatility of individual losses has increased (the consequence of our taking a portfolio view), the increase in annual losses will always be more than off-set by the reduction in annual costs. We should also note that the potential savings would have been even greater had we worked with a multi-year example.

\section{Other advantages}

In addition to the empirical savings arising as demonstrated in the foregoing examples, there are some other benefits. For example, less time, effort and expense is spent on renewal negotiations compared to annual, mono-line programmes and insurance premium costs are more predictable over a longer period. Significant reductions in the quantity of policy related paperwork are also possible, which also provides the opportunity to negotiate common clauses for large parts of any agreement covering multiple risks.

\section{Structural Advantages of Multi-line products}

One of the advantages of multi-line programmes is that limits can be used more efficiently. This can be seen from the following example, which is illustrated in the diagram after this Chapter (page $37)$. 
Consider a company that insures two risks separately using a traditional approach, for example property and the value of an investment portfolio. For each risk it is prepared to accept a GBP 50 million deductible and requires cover for GBP 150 million in excess of this deductible. Assuming the upper limit is not exceeded, the company's worst position will be if GBP 50 million losses develop on both programmes, leading to a loss of GBP 100 million overall. The maximum claim under the policies would be GBP 300 million on two losses of GBP 200 million each.

An alternative approach is to purchase cover for aggregate (i.e. both property and investment) losses in excess of a GBP 100 million deductible up to a limit of GBP 400 million. In comparison with the conventional approach the multi-line policy increases coverage by responding fully to large combined losses, regardless of their composition (area $\mathrm{A}$ in the diagram). However, it does also reduce cover for low losses in one line if there are also small losses in the other line (area B in the diagram).

Theoretical considerations such as those outlined above would lead us to expect that in most cases the premium payable for the multi-line programme would be lower than that for the two mono-line programmes. This is supported by the fact that the premium saving in respect of the reduction in low level cover (i.e. high frequency, low severity) is likely to be high, while that for the increase in high level cover (i.e. low frequency, high severity) is likely to be low.

Although we have only here considered a multi-line programme, similar arguments can be used for multi-year programmes where aggregate limits apply over the whole period. Multi-line, multi-year programmes would again combine both types of benefit.

\section{Limitations of Multi-year, Multi-line Products}

An important underlying assumption of the foregoing type of analysis is that the provider of the combined product is able to price each element of the risk equally competitively. Despite the undoubted convergence of the capital and insurance markets, it has not been sufficiently demonstrated that those companies with a predominantly insurance industry background are efficient at pricing financial risks. This is one of the reasons cited for the relatively slow take-up in such products, commented on, for example, by Brandman J. (1999) and Raschewski, T. (1999). However, the theoretical arguments are equally strong when poorly correlated insurable risks are combined, or even risks of which one or more may previously have been uninsurable. Examples of both situations will be given in Chapter 4. Additionally, there are insurance companies who 
would claim to have the necessary expertise, as quoted in Brandman, J. (1999) in respect of Swiss $\operatorname{Re}$ 'We use the financial markets to manage our financial risk dynamically because it's a very liquid and efficient market.... What you need is to have the right people, the necessary capacity and the technology to handle integrated products. If you are able to develop a common language and to line up different skill sets and knowledge then it works without a joint venture with a bank."

\section{Alternative Risk Transfer and Integrated Risk Management}

It is possible that there are more definitions of Alternative Risk Transfer than there are of risk management. On a narrow basis the term may be defined as any method of transferring risk to a third party other than by using a conventional insurance policy, e.g. by risk securitisation, insurance derivatives or contingent capital. More broadly, the term encompasses all 'non-traditional' means of approaching the risk financing process, including self insurance (through a deductible, retained excess, or captive), risk retention groups, finite risk, etc.; this is the sense in which it is used, for example, by Bannister, J. E. (1998). It will be immediately apparent that at least one of the product types listed in the broader definition is an integrated risk management product, i.e. finite risk, and a cursory inspection of the inventory of sophisticated insurers/reinsurers will reveal that integrated products are usually placed under the ART or 'New Markets' heading. We may conclude that while most integrated risk products could be categorised as ART, there are many ART products that do not feature integrated risk. A useful framework for the analysis of risk financing techniques is contained in Punter, A. (2000), in which it is found convenient to consider three 'baskets': new risks/old capital (e.g. the incorporation of hitherto uninsurable risks within multi-line programmes); old risks/new capital (e.g. catastrophe risks placed directly in the capital markets using bonds); and new risks/new capital (e.g. weather derivatives). Another useful source is Shimpi, P. A. (1999), which also attempts a categorisation of integrated risk management products based on the degree of integration involved.

\section{Providers of Alternative Risk Transfer and Integrated Risk Management Products}

Although we will consider some actual product offerings and examples of their use in Chapter 4, it is convenient to review here the likely providers of integrated risk products. There are two obvious theoretical possibilities: the capital markets and the insurance markets. The economic relationship between the insurance and capital markets is explored by Dickinson, G. M. (1998). His analysis clearly demonstrates the significant inter-relationships that already exist between them and concludes that whilst there are obstacles in the road, it is likely that ART products will be developed 
that can be used by insurers/reinsurers in their own risk financing arrangements; some of these are likely to involve contingent, or kanban, capital, but others could be further developments of integrated products already used by some insurers for such purposes, e.g. double trigger policies. There is, of course, no reason why the trigger for a contingent equity arrangement cannot be related to a combination of risks, as in a conventional double trigger policy.

The providers of double trigger products and contingent capital have, thus far, mainly been reinsurers rather than banks or other capital markets participants. This is mainly because of the roadblocks mentioned above, which are examined in more detail by Shimpi, P. A. (1997) and largely relate to the lack of tradeability of risk. Until such times as a satisfactory method for trading risk is devised, it is unlikely that the capital markets will be comfortable providing, for example, long term equity put options, which is essentially what contingent equity comprises. However, catastrophe bonds are becoming an increasingly common feature of capital markets and despite the theoretical imperfections of risk securitisation involving bonds, they seem set to grow as a proportion of total bond issuances.

Dickinson has also pointed out (private communication, $22^{\text {nd }}$ August 2000) that there seem to be at least two reasons why truly integrated products have not evolved naturally from the 'packaged' insurance products that have fuelled much commercial lines growth in the United States over the last few decades. The first is that insurance companies could find it difficult to issue certain types of integrated policies that were not specifically permitted under the relevant state or federal legislation $^{7}$. It may also be observed that in the US, in particular, there could be additional complications with risk based capital. Second, even where a domestic company has the capacity, expertise and will to write such policies, it may be forced to do so off-shore, thus dispelling the illusion of a one-shop stop.

We must also remember that some integrated products involve combinations only of financial risks, e.g. interest rates and exchange rates. These have been available since the mid-1990's ${ }^{8}$ and have been provided almost exclusively by banks, who are able to hedge the underlying risk using more conventional and widely traded derivatives. Equally, insurance companies have been promoting the concept of multi-line policies covering insurable risks only (e.g. D\&O/Fidelity) for at least the last decade.

\footnotetext{
7 This would also probably be the case in the European Union.

${ }^{8}$ If one defines multi-year (e.g. average rate options) or multi-currency (e.g. basket options) derivatives as integrated products, then they have been around even longer, certainly since the mid-1980's.
} 
The interface between insurance companies and banks is examined in detail by Dickinson, G. M. and Dinenis, E. (1993) and some of the problems inherent in such relationships, at least from the banks' perspectives, are identified. In the period since that paper was published bancassurance (or allfinanz) has continued to be an ideal pursued by many banks and several insurers, but the number of really large scale mergers between major banks and major insurance companies has been extremely limited (i.e. Credit Suisse/Winterthur and Citicorp/Travelers). There is thus still considerable scope for cooperation between banks, insurers and even brokers, all of whom have individual skills that can be brought into play in creating integrated risk and other ART products. In fact, this is evidenced by the lists of advisers published along with most recent risk securitisation deals and the announcement of alliances such as those between Axa and Paribas (Financial Risk Strategies - "FIRST") and Royal Bank of Scotland and Royal \& Sun Alliance (Financing Solutions) in 1999, both reported by Banham, R. (1999).

The question of who is likely to be able to provide integrated products is also addressed by Sanderson, S. M. (1999). He questions several of the traditional arguments often quoted in favour of the capital markets, e.g. their relative size and supposed distribution and other cost advantages relative to the insurance markets. In his view, although the market for integrated risk products is only just emerging and there is undoubted convergence between the two markets, the insurers may have a long term structural advantage in providing such products.

One interesting question is whether soft insurance markets encourage or discourage the growth of new products such as those we are considering here. It has been generally reported that the hard markets of the 1970's and 1980's encouraged the growth of alternative capacity, such as Bermuda, and the greater use of captives. This seems to be supported by a recent comment from a leading broker "One reason for so few of these [integrated risk] deals having been done is that the traditional insurance market has sold its wares recently at rock-bottom (and sometimes suicidal) rates" (private communication with author, $27^{\text {th }}$ April 2000). However, an alternative view is proposed by Mark Butterworth, Chairman of AIRMIC, in Brandman, J. (1999) "With the continuing soft market in the reinsurance arena, there is a lot of market capacity out there with insurers looking to write different types of risk." 


\section{Structural Implications for Companies}

Despite usually negligible tax advantages and an increasingly questioned role in real cost reductions, the number of captive insurance companies continues to proliferate. One of the main explanations of this seems to be the increased flexibility they permit their parent companies in arranging coverage with operating subsidiaries compared to that which they choose to buy in the marketplace. For example, a parent may allow an operating subsidiary to take only a GBP 100,000 deductible on its property insurance bought from the captive and charge a premium commensurate with this, but purchase third party reinsurance with a deductible of GBP 1 million. The same

principle applies to those companies whose Treasury departments operate an 'in-house' bank. In such cases subsidiaries may be required (or choose) to hedge exposures above a de minimus limit, say USD 100,000 million, but they may do so only with the in-house bank. On writing the hedge contract the in-house bank first has the opportunity to off-set any opposite exposures and can then arrange third party cover for net exposures in excess, say, of USD 1 million. The logical consequences for those companies with substantial exposures seeking to manage financial and insurable risks on an integrated basis is clear:

- if they are operating a captive insurance company, but not an in-house bank, it probably makes sense to set up the other (and vice versa);

- if you are going to have a captive insurance company and an in-house bank, it may well make sense to have them both in the same legal vehicle (fiscal and regulatory issues permitting); and

- even if they are not in the same legal vehicle, their activities should be highly coordinated.

These and some associated issues are discussed by Sanderson, S. M. and Koritzinsky, A. G. (1999). 


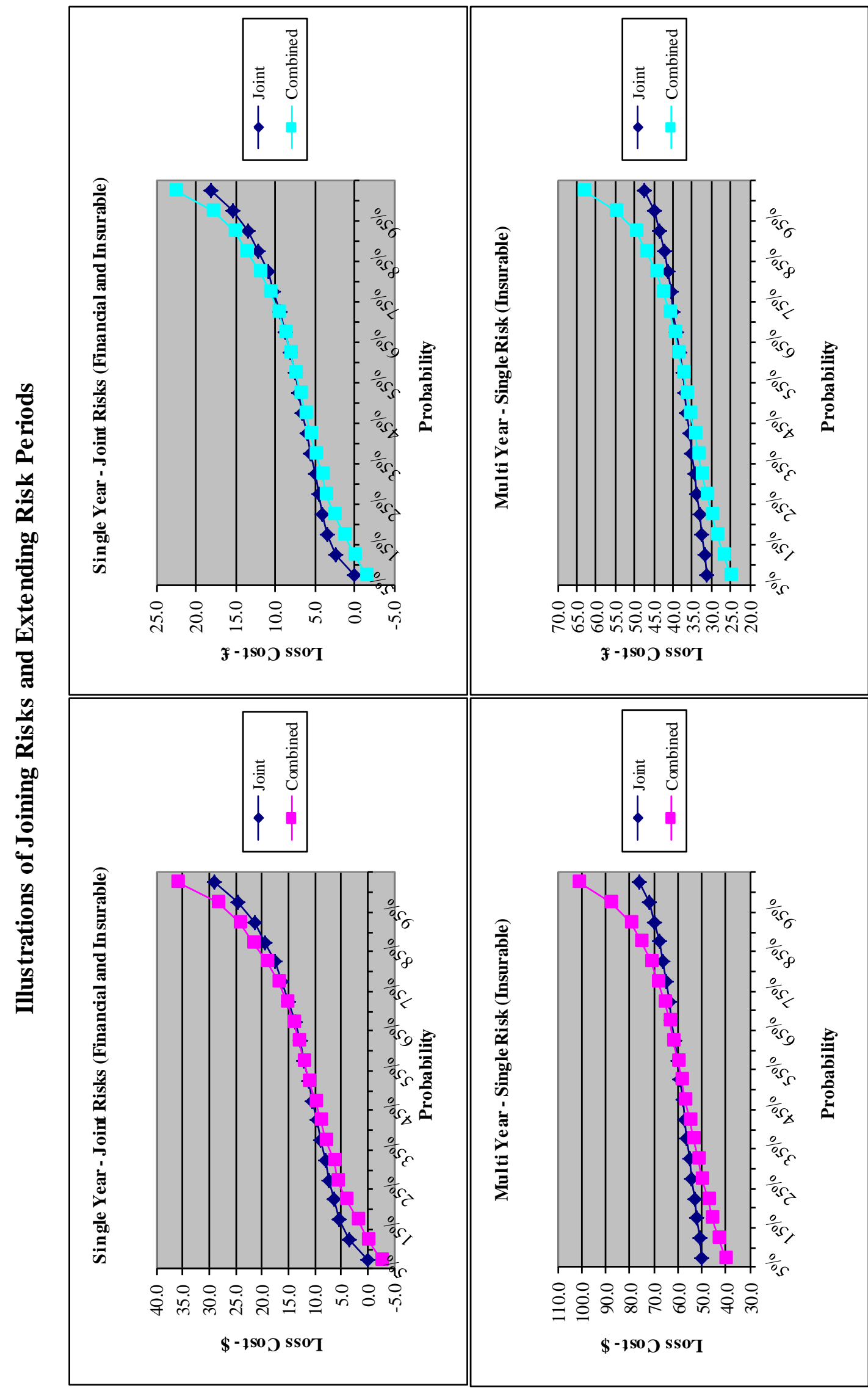

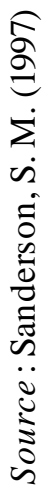




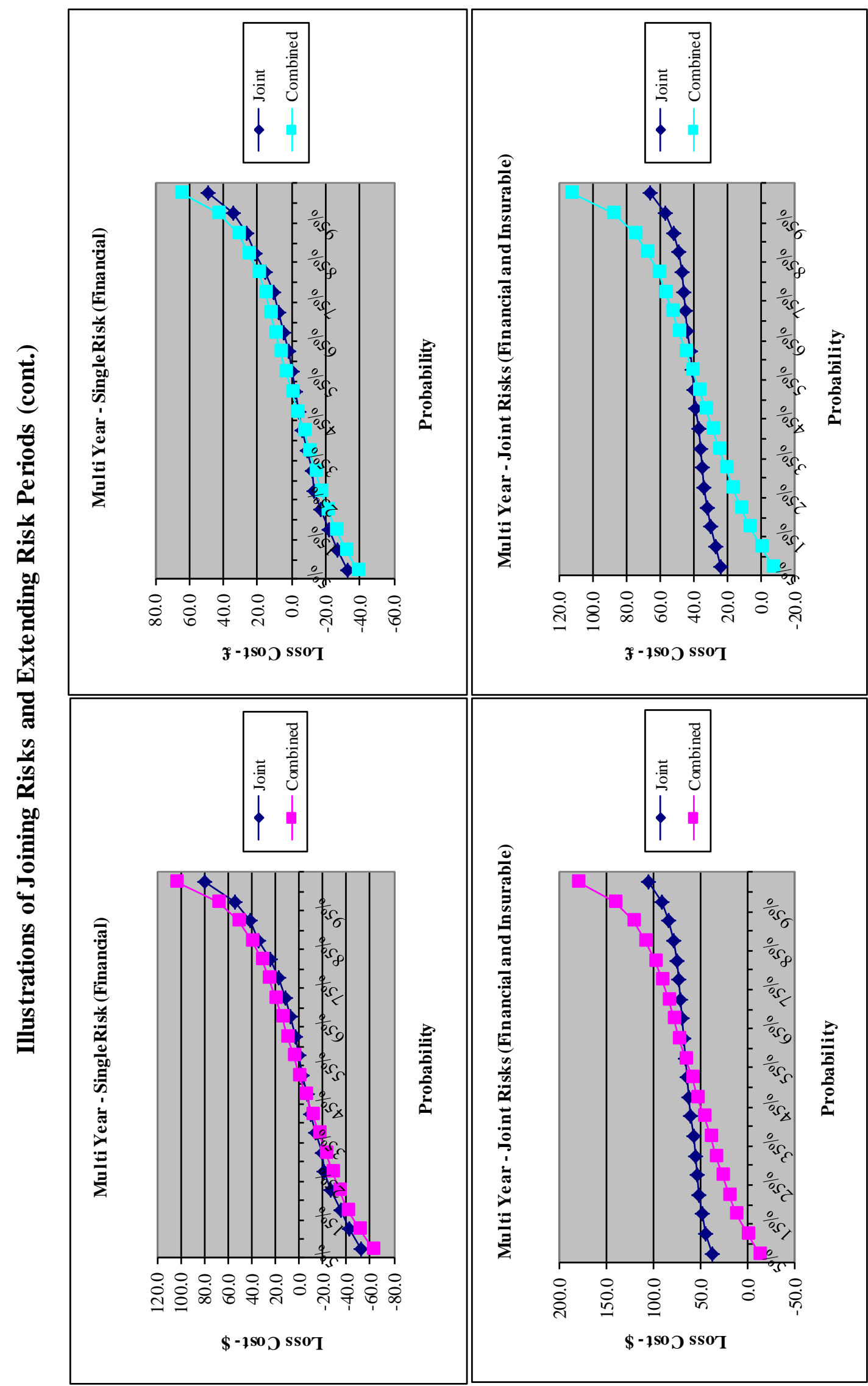

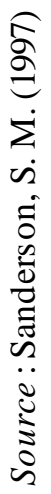




\section{Comparison of Conventional and Multi-Line Programmes}

\section{Conventional Risk Management Programme}

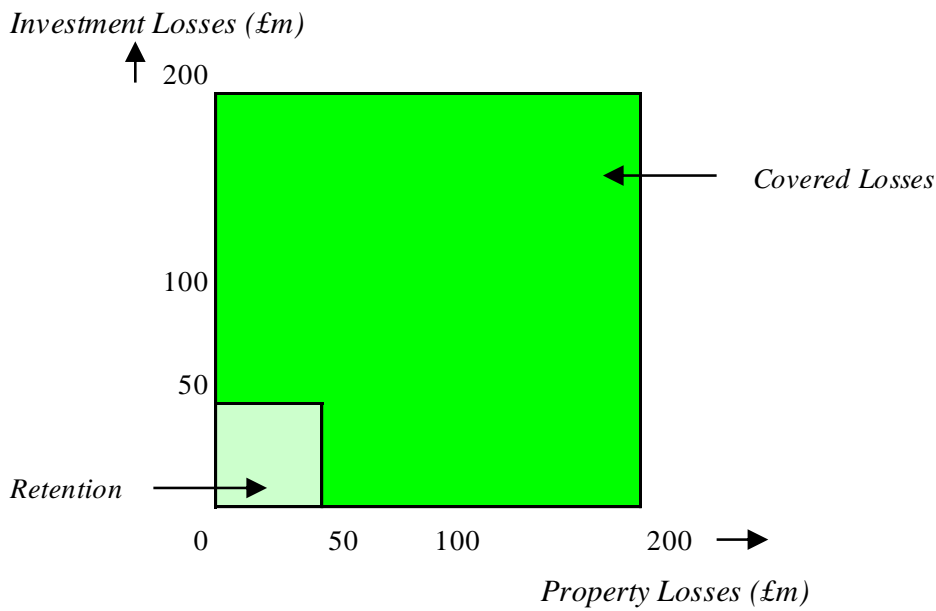

\section{Multi-Line Risk Management Programme}

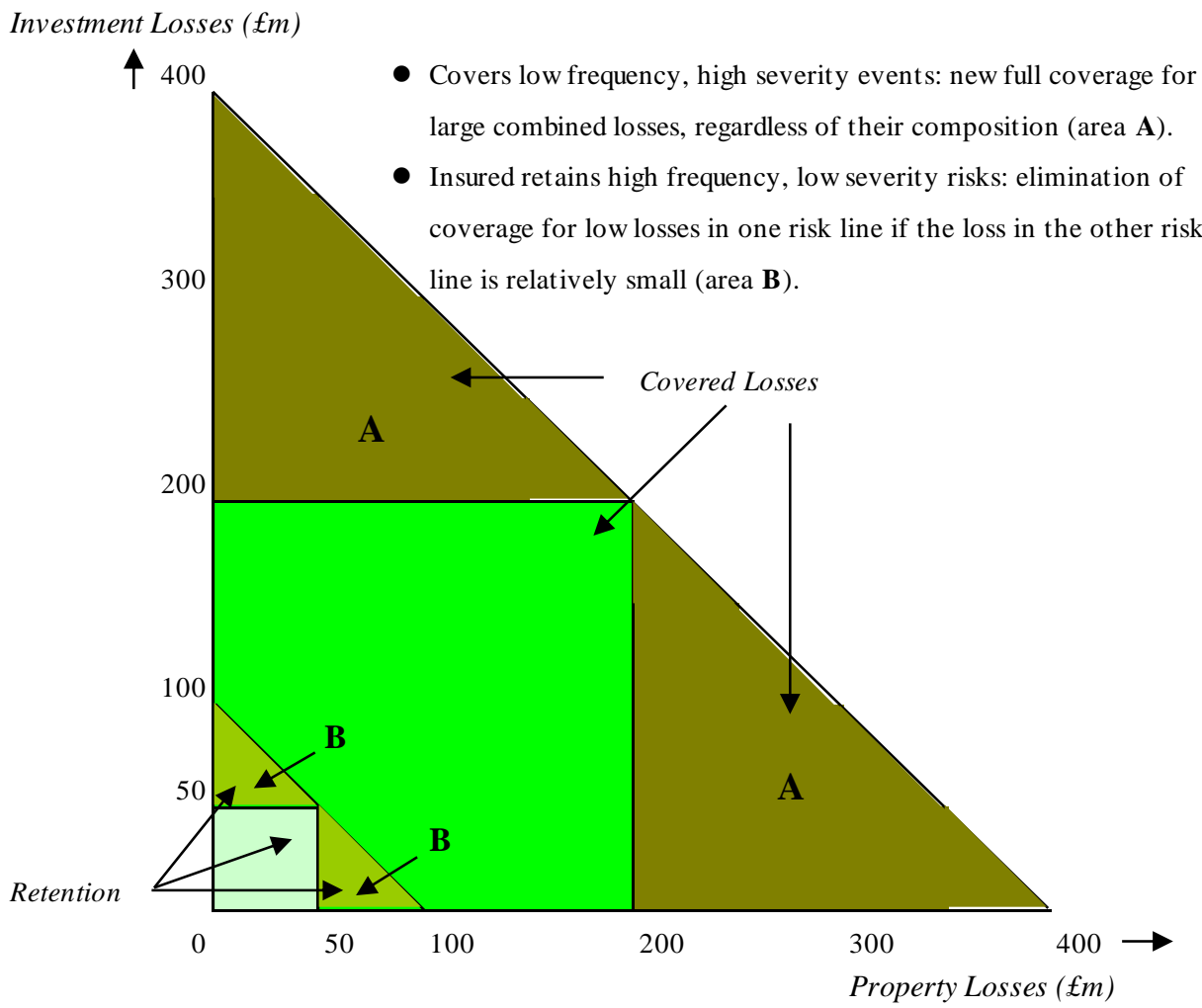

Source: P. A. Shimpi, Integrating Corporate Risk Management, Swis s Re New Markets, 1999. 


\section{Chapter 4}

\section{Integrated Risk Management: some products and possibilities}

\section{Introduction}

Although a number of market participants have products that they describe as proprietary, the simple fact is that all have to be tailored to the particular circumstances of the enterprise concerned. The result is that the final product in each case will have design features arising from both internal risk managers and external risk advisers, which, in the latter case, can be from brokers, or insurers, or both. This fact is readily acknowledged by those who provide the basic products and is commented upon by Banham, R. (2000). In the remainder of this Chapter we shall describe some of these proprietary products and also summarise a few of those examples of their use that have been widely reported.

\section{Product One: Asian or Average Price Currency Options (Generic)}

These are options where the pay-off depends on the average exchange rate during at least some part of the life of the option. Average price options are always less expensive than vanilla options of the same maturity and are arguably more appropriate in certain circumstances, for example if a company is receiving cash from a foreign subsidiary spread evenly over a year. A good source of material on these and other exotic options is Hull, J. C. (2000).

\section{Product Two: Barrier Options (Generic)}

In such options the payoff depends on whether the underlying asset's price reaches a certain level during a certain period of time. There are two main sub-types: knock-in (where the option only comes into existence when the underlying asset reaches a barrier); and knock-out (where the option ceases to exist when the underlying asset reaches a barrier). Again the price will be lower than that for an otherwise similar vanilla option. We mention these options due to their structural similarities to multi-trigger insurance policies. 


\section{Product Three: Basket Aggregate Stop Loss Policies (Generic)}

These insurance policies are designed to provide a cap on the total amount of risk a company retains, unlike per-occurrence retentions that could reduce a firm's cash flow in a high loss frequency year. They may be combined with a single attachment point for several lines of coverage, allowing companies to buy greater capacity very efficiently. Certain categories of risks are usually not included in basket average arrangements, e.g. D\&O, special risks, political risks, etc. See Thornhill, W. and Derksen, A. (1998) for further details on this and similar products.

\section{Product Four: Basket Currency Options (Generic)}

These are options where the pay-out is dependent on the value of a portfolio (basket) of currencies valued against a common or 'pivot' currency; the option can be exercised in its entirety or not at all, i.e. there are no individual options on the constituents of the basket. It is quite possible for the weightings of the individual currencies to be different. The lower the correlation between the two currencies, the lower the chance of a pay-out and the lower the premium. Such options may be used, for example, by multinational companies seeking to manage the earnings of a group of overseas subsidiaries.

\section{Product Five: BETA (Multi-line, multi-year risk transfer - Swiss Re)}

This is a bespoke product that covers both property and casualty risks. The emphasis of the product is on true catastrophe losses and takes advantage of the reduction in risk inherent in a portfolio approach. Aggregate and per-occurrence limits are provided over a three year initial period, with an option to extend for a further three years, subject to certain conditions. (Source: Swiss Re, BETA, 1997.)

\section{Product Six: Double Trigger Policies (Generic)}

This term is used to describe a very wide range of insurance policies where activation is determined by two underlying events rather than the more normal one. An example might be where an oil company felt it could afford to self-finance a property loss unless the price of oil, and therefore its 
profits, fell to a low level. Coverage might therefore be contingent on the loss occurring and the price of oil falling below $60 \%$ of the year's opening level. Another example would be an insurance company that purchased reinsurance contingent upon claims exceeding a certain level and an appropriate stock market index closing the year at less than $80 \%$ of its opening level. More complex examples of double trigger strategies are given in Schön, E., Boccichio, V. and Wolfram, E. (1998). They have an analogy in the financial markets in double trigger options, where the right to exercise the option (e.g. a sterling/dollar call) only occurs if a separate condition has been met (e.g. euro interest rates below a specified level). Double trigger policies are easy to understand and intuitively appealing and it may well be that the conclusion in ACT (2000) is correct "We will see much more of dual trigger policies".

\section{Product Seven: EEPP (Enterprise Earnings Protection Policy - Reliance National)}

The product covers natural and man-made hazards together with business and operational risks (e.g. decreases in the demand for goods and services, supply chain and distribution problems, weather related risks, increases in raw material costs, etc.); it has the possibility of being extended to cover financial exposures (e.g. interest and exchange rate risks, commodity prices, etc.). It is written on a first party claims made basis that works with existing policies, serving as an additional layer of cover against catastrophic property and casualty risks whilst providing primary coverage for the business and operational risks. The policy is unusual in that it is written on an all-risks basis, i.e. it covers any losses other than those that are specifically excluded, as opposed to defined perils. The maximum cover available is USD 50 million or $20 \%$ of earnings (as defined), whichever is greater, with a USD 5 million deductible, and it pays out in cash. Thus a fall in earnings from USD 100 million to USD 80 million would result in a payment of USD 15 million (USD 20 million, less USD 5 million). The product is reinsured with Swiss Re. Some further details are contained in Falloon, W. (1999).

Product Eight: GAMMA (Index-linked, multi-line, multi-year risk transfer - Swiss Re)

This is an enhanced version of BETA. The contract length is from five to ten years, with premium and coverage levels adjusted according to capital markets and hazard indices. It also covers financial as well as insurable risks. (Source: Swiss Re, GAMMA, 1999.)

Product Nine: Interest Rate Contingent Currency Options (Generic) 
These are options where the pay-off is only made when the currency element of the option is in the money and a specified interest rate is within a given range. They may be used, for example, in connection with hedging the interest costs of foreign currency debt. Dehnad, K. (1996) provides an example of the application of this and a number of other similar instruments

Product Ten: MACRO (Multi-line, Aggregated and Combined Risk Optimization - Swiss Re)

This a bespoke product that may include a number of insurable risk coverages (e.g. property and casualty, fidelity, etc.) and several financial risk coverages (e.g. exchange rates, interest rates, commodity prices, etc.). By integrating different risk management techniques, the product eliminates the risk of over-hedging and reduces costs. It is designed to provide coverage specifically for severe losses, while smoothing the volatility of expected annual losses. Aggregate and per-occurrence limits are provided over a three to five year initial period, with an option to extend for a further three to five years, subject to certain conditions. Additionally, automatic or optional reinstatement can be provided and sub-limits may be applicable for selected coverages. A profit-sharing commission feature based on volatility and loss experience may also be available. (Source: Swiss Re, MACRO, 1997.)

Product Eleven: RiskFusion ${ }_{(S M)}($ Multi-line, multi-year risk transfer - Marsh)

This is a flexible product available for the coverage of a wide variety of insurable and financial risks over periods of up to, typically, five years, although with the option of evergreen renewals (under certain conditions). For the purposes of this product, financial risks include weather variations as well as foreign exchange rates, interest rates and commodity prices. Insurable risks would include: workers compensation, general liability, property, business interruption, cargo/marine, D\&O, etc. (Source: Marsh, RiskFusion ${ }_{(\mathrm{SM})}$ Concept, 1997.)

Product Twelve: Risk Solutions (Multi-line, multi-year risk transfer-Cigna/XL Insurance)

This is a very similar product to Swiss Re's Beta, described above. 
Example One - Honeywell

The decision by Honeywell to pursue an integrated approach to risk management was taken in 1997 after more than a year of analysis, the main external advisers being Marsh and AIG; this process is described at length by Barnett, J. and Meulbrook, L. (2000) in their HBS case study. The product devised combined both insurable and financial risks over a three year period, with excess towers over the insurable risks, but not the currency risks. There were significant differences in coverage on both the insurable and financial risks portions in addition to the 'simple' combination of risks.

A particular feature of innovative insurance programmes is the criticism they tend to generate from advisers who failed to win the business themselves or come up with the idea in the first place. In this case a good example is the comment from a leading broker "Honeywell was the first but it was a bit of a fudge (a race to be first?) and cratered after one year" (private communication with author, $27^{\text {th }}$ April 2000). Whilst this may be true, it is something of an over-simplification. Not long after the programme was finally put in place, Honeywell merged with (in fact, was effectively taken over by) Allied Signal and Marsh was replaced by Aon. Banham, R. (2000) provides the following quotation from Aon "We did an analysis of their integrated risk programme for them and learned it wasn't as cost effective as they had hoped. Honeywell was the classic situation where someone had this really novel idea, celebrated its completion, and then never stopped to see if it was a good idea after all. They're back to normal now with a conventional structure." Professional courtesy seems not to be a feature of the insurance broking markets.

What does seem to be true in this case is that Honeywell could have transferred the insurance and financial portions of the programme more efficiently within the insurance and capital markets respectively. More fundamentally, the fact that the financial portion of the programme related to the hedging of currency translation and exposure of earnings using at the money call options would in any case have been questioned by many treasurers, especially when seeking merger related cost savings.

\section{Example Two - United Grain Growers}

Following the publication by the Toronto Stock Exchange of corporate governance guidelines on risk, this company worked with its principal advisers, Willis and Swiss Re, to identify 32 'new' risks (e.g. counter-party (non-credit) risk, credit risk, weather risk, inventory risk and various grain commodities, such as barley and wheat) in addition to its 17 customary insurable risks. Various 
structures were considered by the company before the final form was settled. The three year deal as finally written was described in The Economist ("Outsourcing capital", November 27, 1999) as well as by Banham, R. (1999 and 2000). Under the programme, a reduction in grain volume is treated as a loss, drawing from the same aggregate risk protection afforded property and casualty risks in the integrated policy. To avoid moral hazard and over-complexity, grain volumes are linked to an external index, although this does introduce some basis risk. As with any other integrated policy, there is a risk that the non-hazard exposure will produce losses blowing through the entire aggregate policy. This particular transaction is also interesting in so far as the reporting makes clear that the evaluation by the company took into account the fact that insurance offered a lower cost of capital alternative to traditional debt and equity, as discussed in Chapter 3.

\section{Example Three - Bank Gesellschaft Berlin AG}

A few details of this deal, Germany's first integrated structure, are given by Raschewski, T. (1999). Key features were: over 1300 covers reduced to one single combined limit; similarly, over 1300 policies replaced by a single policy document; terms and conditions rewritten and streamlined; and premium savings of $20 \%$ through the basket effect and a reduction in limits.

\section{Example Four - Exxon Mobil}

Prior to its merger with Exxon, Mobil Oil purchased a form of Swiss Re's Beta policy, described above. The policy was not renewed in 1999 on an integrated basis, it being reported in Banham, R. (2000) that the company had obtained a better deal by pitting different insurers against each other competing on a line-by-line basis.

\section{Example Five - Huntsman}

This is a similar situation to that of Exxon Mobil described above, where a three year multi-line deal was not renewed and the company reverted to a multiple provider solution on the grounds of greater cost-effectiveness. Banham, R. (2000) reports that the product involved was Cigna/XL Insurance's Risk Solution. 
Example Six - Union Carbide

Although reported by Banham, R. (2000), it has not been possible to identify the three-year multi-line product, which was probably Beta or Risk Solution. However, unlike the Huntsman and Exxon Mobil deals described above, the policy was renewed for a further three year period after its expiry in 1999.

\section{Example Seven - British Aerospace}

This case is included more as an example of extending the boundaries of what is considered insurable risk rather than as an integrated risk management product per se; however, it does have some points of resemblance to the EEPP described above. In common with other aircraft manufacturers, BAe leases some of the aircraft it builds to customers on very flexible terms. In the event of aircraft being returned earlier than expected, BAe would incur losses. The policy entered into by BAe against a one-off premium payment of GBP 38 million for 15 years of cover protects the company from the risk of sale and lease income falling below GBP 2.4 billion per annum. By combining this insurance protection with an internal provision of GBP 500 million, the company estimates that it has eliminated $90 \%$ of the accounting risk of income from its lease book dipping below the budgeted figure. Advisers to the structuring of the deal were Marsh and Royal \& Sun Alliance.

Example Eight - TRW Inc.

As it currently stands, the TRW combined programme integrates the following individual programmes using a variant of RiskFusion ${ }_{(\mathrm{SM})}$ : general liability, product liability, employers' liability, workers' compensation, crime and property/ocean cargo. A combined annual aggregate retention applied to the constituent programmes, sitting over which is a 'tower', comprising a number of integrated excess layers, generally with similar occurrence and aggregate limits. The only major programmes outside of the combined programme are: aviation, $\mathrm{D} \& \mathrm{O}$ and special risks. 


\section{Chapter 5}

\section{Enterprise Risk Management and Integrated Risk Management: some opinions}

\section{Methodology}

At an early stage in the investigation of the issues outlined in the Introduction, it became clear that it would be potentially valuable to try to understand the views of a cross section of organisations towards enterprise risk management and integrated risk management, rather than to essay these solely from the ivory towers of academia. Instead of sending a questionnaire to a large number of industry participants and hoping for a reasonable response (which anyway would have been impractical in the time available), it was decided to target questionnaires at a very limited number of senior people in key organisations and, where possible, to take them through the questions and answers in person. For this reason the questionnaire was designed to be of such a length that it would take approximately forty five minutes to answer when used as the basis for a structured interview. Given the topicality of Turnbull and firm-wide risk management, it was decided to devote the first part of the questionnaire to this topic (questions 1 to 5), then moving on to integrated risk management in the second part (questions 6 to 10). The questionnaire is given in the Appendix in the form in which it was distributed, while individual questions and a summary of the responses to each are given below. No attempt was made to create a random sample of respondents or to analyse the responses statistically. In some cases answers provided to one question have related to other questions; where this has occurred responses have been adjusted as necessary.

\section{Participants}

The categories of participants that it was desired to include were representatives of:

(1) major accounting firms with risk management practices;

(2) major banks with risk management product teams;

(3) major insurance brokers with risk management practices;

(4) specialist insurance brokers; 
(5) other risk management consultancy practices;

(6) major insurers/reinsurers;

(7) corporates.

Participants were given the opportunity to participate on an anonymous basis where they felt commercial issues could be at stake, although only two accepted this invitation. However, the understanding in each case was that individuals were responding as such and not as representatives of their firms. Of the fourteen organisations invited to participate, twelve accepted; one of those that did not do so on the grounds that it had very recently decided to exit the business of international commercial risk management. One organisation was so keen to participate that two of its senior executives completed the questionnaire separately (and with only occasionally disparate views). These firms were, using the same categorisations:

(1) Deloitte \& Touche, PricewaterhouseCoopers (i.e. two major accounting firms);

(2) Citigroup and another major bank (i.e. two major banks);

(3) Aon Group Limited, Marsh, Willis (i.e. three major brokers);

(4) United Insurance Brokers Limited (i.e. one specialist insurance broker);

(5) McKinsey (i.e. one major consultancy);

(6) Prudential Group plc, Swiss Re (i.e. two major insurers/reinsurers);

(7) a major US based engineering and technology company (i.e. one major corporate).

It will be observed that the majority of these firms are genuinely global (albeit predominantly US based), with those that are not being mainly UK based.

\section{Questions and Responses}

Q1. The Turnbull Guidelines on internal controls arising out of the Combined Code require UK listed companies to adopt a systematic approach to risk management in its widest sense, what might be called Firm-Wide or Enterprise Risk Management. Do you believe that the implications of Turnbull have yet been fully appreciated by UK listed companies?

A1. A slim majority of respondents answered yes to this question, but many of those added caveats and the remainder were pessimistic. Several suggested that larger firms (e.g. FTSE-100 constituents) were on board, but that the evidence for smaller firms was mixed or even 
predominantly negative. Financial institutions, as a class, were also viewed favourably in terms of understanding, mainly because of the nature of their business and the keenness of the Financial Services Authority as a new supervisor. Others differentiated between an understanding of the practical implications of Turnbull (generally well understood) and the philosophical implications (generally not appreciated). One respondent suggested that while CEO's and CFO's were generally Turnbull aware, this awareness was not seeping down into lower levels of management, except where the direct involvement of individuals was necessary to achieve compliance (e.g. Internal Audit and Treasury), thus slowing cultural change. Among the explanations volunteered for the slowness of take-up of some companies were the difficulty in identifying 'value added' in risk management activities and the fact that some risks are simply very hard to quantify (e.g. 'reputation risk'). One respondent disagreed with the emphasis of the question and felt that the key to the implementation of Turnbull was the 'embedding' of risk management in the culture of an organisation, which Turnbull indeed suggests. On this basis the respondent felt that virtually nobody was complying with Turnbull. Among those who answered no to the question, there was a general feeling that an inconsistency in what is meant by risk prevents a full appreciation of Turnbull's implications.

Q2. Some companies, of course, already approach risk management in a broad and structured manner. Do you foresee that those that do not will change their approach fundamentally, or are they more likely to do the minimum necessary to achieve the tick of their auditors?

A2. A surprisingly high number of respondents proffered the view that there was a generally increasing trend in the level of risk awareness of companies, quite apart from that driven by the need for Turnbull compliance. However, good intentions were off-set by the practical difficulties and expense often encountered in trying to implement major changes to the risk management process together with a shortage of competent practitioners, making progress usually slow. Real practical problems exist in trying to promote communications between the functions that have to be involved (e.g. Treasury, Purchasing, Manufacturing, etc.), especially in decentralised companies or those with geographically dispersed operations. Realignments of risk responsibility and reporting lines can also often be job-threatening, making the voluntary cooperation of individuals unlikely. Respondents also drew a distinction between the effort expended on strict Turnbull compliance (frequently the minimum required, with guidelines setting a ceiling rather than a floor) and longer term, more far reaching efforts directed to improving risk management strategy and permanently changing the culture of organisations. Even those strongly critical of Turnbull felt that investor pressure would support the increasing trend of awareness, but that it would be a slow process. 
Several respondents suggested that 'bare-bones' compliance would be the norm until another serious problem occurred that could be attributed to adhering to the word rather than the spirit of Turnbull.

Q3. Do you have any views on the fact that the drawing up of the guidelines was delegated to the accountancy profession?

A3. This question provided a diverse range of responses, even from among members of the accountancy profession. At one extreme was the view that Internal Control is all about reporting and that it therefore has to tie in closely to the audit/accounting/control process. Under this view the choice of the ICAEW was almost inevitable. At the other extreme is the view that any additional reporting requirements imposed by an ICAEW committee would lead to a conflict of interest and be regarded as providing "jobs for the boys" or "money for old rope" and would therefore receive a poor response. Deficiencies of the accountancy profession in relation to an appreciation of technology and being forward thinking were also noted. Three respondents pointed out that accounting qualifications have virtually no requirement for an understanding of risk management and/or insurance and that this is also true of most masters degrees in finance and also of most MBA's with a financial emphasis; to the extent that risk is covered in such courses, it is usually on the basis of a very narrow definition. Most respondents felt the guidelines could have been much improved if the committee had a more balanced membership of greater stature, perhaps comprising CEO's and industry analysts as well as accountants. Although some consultation did take place with bodies such as AIRMIC, this tended to be at a late stage and its effect on the final version was not great. The necessity for revising Turnbull after its effectiveness has been tested for a few years was also pointed out by more than one respondent. One respondent observed that Turnbull was acting as a catalyst to CEO's/CFO's, who were increasingly reaching the conclusion that 'insurance man' was not a suitable candidate for the position of Chief Risk Officer, being ill-equipped with the necessary experience and tools for the job, particularly those of a financial nature. Another respondent echoed this thought, observing that few specialist Risk Managers had the real breadth of skills and experience necessary to manage risk on a firm-wide basis, most having progressed through the safety and insurance routes.

Q4. As CEO of a traditionally organised major UK plc, to whom within your organisation would you give principal responsibility for ensuring compliance with Turnbull?

A4. The most frequent response was the CFO, unless the organisation concerned had in place a 
CRO of sufficient seniority. Those who offered an opinion were divided as to whether a CRO should report direct to the CEO or to the CFO. However, the importance of obtaining the buy-in of operational management was also stressed by respondents and some favoured a committee approach, perhaps chaired by the CFO. One respondent pointed out that some current surveys (e.g. Implementing Turnbull - almost 8 months on!, Deloitte \& Touche Enterprise Risk Services, July 2000) were suggesting that in practice the Internal Audit Manager was often the practical choice (a fact that was confirmed by another respondent), while even the Company Secretary was drawing the short straw in some companies. Treasury was mentioned explicitly by two respondents. Another respondent suggested that the non-executive directors should have a supervisory role (possibly through a Risk Committee of the Board, run along similar lines to an Audit Committee).

Q5. Do you have any other strong views on Turnbull?

A5. Among the comments that were received, most related to the fact that, whilst containing sound principles worthy of adoption, Turnbull is sufficiently flawed to be unlikely to make a real difference and that it is inevitable that corporates will view an increased compliance workload as an unnecessary distraction, or simply bureaucracy. It was also pointed out that even if increased disclosure was of marginal benefit to institutional investors, it would do nothing for most small investors. Other specific criticisms included the fact that it was unspecific and lacked teeth. However, one respondent pointed out that although the sanctions for non-compliance with Turnbull are relatively light, with the Financial Services Authority having taken over supervision of the Listing Rules from the London Stock Exchange, a careless attitude to disclosure could conceivably be regarded as a misleading statement under Section 47 of the Financial Services Act (as leading to the creation of a false market in securities), with possible serious ramifications for directors. Another respondent felt that the passing of the Financial Services and Markets Act would also act as a driver for change. It was also pointed out that, during the consultation process, AIRMIC recommended that the public reporting of risk should include a discussion of how the business finances residual risk, i.e. what reserves/contingency funds/insurances are in place to meet the costs of things going wrong. The benefit of this would be to understand the resilience of the business to risk events and it would make the directors think more clearly about quantifying residual risk.

Q6. Various tools, mostly bespoke, have been developed for the integrated management of insurable and financial risks, for example 'double trigger' insurance policies. Do you feel that Turnbull in the UK, and similar regulations elsewhere, will have a significant positive influence on the speed of development and acceptance of such products? 
A6. The consensus response to this question was no. (More than one respondent felt there was anyway more hype than reality.) Among the supporting reasons given were: (a) that Turnbull focuses on the comprehensive identification of risks, not managing them (either on a traditional or an integrated basis); (b) that senior management's understanding of integrated risk management techniques is likely to be weak; (c) claims are more difficult to adjust with multi-line policies and settlement may be delayed; (d) only a small proportion of the total risks faced by a company (typically 20\%) is insurable or hedgeable (i.e. the balance are operational as defined herein); (e) inherent conservatism and resistance to change within the insurance sector at large (especially in the $\mathrm{UK}$ ); and (f) a poor understanding of corporate finance by insurance practitioners and vice versa. The importance of recent regulatory changes inimical to risk management was also pointed out by one respondent, particularly FASB 133 in the US, which requires the marking to market of all derivatives contracts. Since UK companies with a US listing have to produce US GAAP financial statements, this can also have an effect on UK companies. This has the effect of making it difficult to incorporate financial risks in a multi-line policy and to avoid the result being classified as a derivative for reporting purposes. It was also pointed out that significant savings only really begin to accrue, after costs, with the really large deals (i.e. > USD 1 billion); however, these are of such a size that they need to be syndicated and it can be difficult to identify two or more large insurers that take a similar view of such risk portfolios.

Q7. The literature would suggest an upsurge of interest in multi-line, multi-year insurance products. (i) Do you believe that there has been higher than average premium growth from such products over the last five years? (ii) Do you believe that there will be higher than average premium growth from such products over the next five years? (iii) What factors could make you wrong about your forecast?

A7. In retrospect this question was clearly poorly constructed. The following summaries of responses to the three sub-questions also deal with some background issues not directly raised by the question. (i) The use of multi-line, multi-year products has grown from almost nothing five to ten years ago, but seems recently to have reached a peak. The main reason for this appears to have been fewer than expected financial benefits, other than those arising from the more efficient use of limits. Also, with premium rates soft as they have been for the last few years, corporates have had little incentive to seek further rate reductions through 'innovative' products, particularly in a marketplace not well structured to provide such solutions. (Typically, different underwriters specialise in the various business lines likely to be comprised in a multi-line policy.) Thus 
although premiums generated by such products have increased substantially in percentage terms, they have normally substituted premiums for the specific programmes that have been replaced. (ii) In present market conditions respondents felt there was little likelihood of the market share of such products changing dramatically. One reason stated for this is the pace of change affecting other aspects of business, dealing with which is viewed as taking a priority position. However, another respondent observed that the overall reduction in acquisition costs associated with multi-year policies was such that more insurers would be pursuing these, there being no strict rationale for single year policies. (iii) Among the factors identified were: (a) a significant hardening in insurance market conditions; (b) a demand from corporates for new types of coverage that are more likely to be available as part of a multi-line product than as a stand-alone product (e.g. product recall liability); (c) a further consolidation in the underwriting market, resulting in insurers who have expertise and appetite for multiple lines of business; (d) increased use of captives by corporates; (e) increased ability of providers to explain the benefits convincingly to CFO's; and (f) new legislative or regulatory obstacles being placed in the way of such policies.

Q8. Multi-line financial risk management products have also become more common over the last five years, albeit probably to a lesser extent. (i) Do you believe that there has been higher than average income growth from such products over the last five years? (ii) Do you believe that there will be higher than average income growth from such products over the next five years? (iii) What factors could make you wrong about your forecast?

A8. Again the question was not well received and the following summaries contain syntheses of the various comments. (i) Generally the feeling was that this was not the case, although some specific examples of exceptions were noted, e.g. 'Asian' or average price currency options and 'quantos', i.e. cross-currency derivatives. (ii) Again it was felt unlikely that there would be a dramatic change over the next five years. One reason stated for this was the unfriendliness of accounting standards and tax treatment. (iii) Among the factors identified here were: (a) a significant and prolonged increase in the volatility of financial markets generally; (b) a dramatic improvement in the quantitative skills of corporate financial risk managers; and (c) development of easily understood and reasonably standardised products. One respondent raised the issue of where 'contingent capital' products should be included, if at all, on the grounds that they could be a surrogate for multi-year, multi-line products; this was one area where he felt there had been significant growth in the last year and there was a strong likelihood of this continuing, possibly because they were of greater intrinsic interest to CFO's. 
Q9. True integrated insurable/financial risk management deals, e.g. Honeywell, have so far been relatively few and far between. (i) Given that the technology has existed for over a decade, why do you feel this is? (ii) Do you feel there is likely to be an acceleration in growth over the next decade. (iii) What factors could make you wrong about your forecast?

A9. A wide cross-section of responses was received to each of these questions. (i) Among the factors identified were: (a) considerable scope for the improvement of 'conventional' risk management programmes in many companies; (b) structural issues associated with the lack of a single individual responsible for coordinating risk management in its widest sense in most organisations (i.e. the 'silo' mentality for risk management); (c) the complexity and expense of putting these programmes together (especially external advisory costs, e.g. legal, tax and accounting); (d) the absence of a 'corporate finance' framework for evaluating the benefit of 'investment' in insurance; (e) practical difficulties in allocating the cost elements of such programmes and the benefits between business areas; (f) the failure of providers to master the technology; (g) de-jargonisation of the risk management function; (h) innate conservatism within the risk management profession; (i) relatively cheap conventional insurance; and (j) the existence of dominant risks, e.g. jet fuel price in the airline industry, which it is difficult to reduce by combining other smaller risks. Two respondents felt that there had probably been more deals than the question implied, but that public reporting of them had been limited. Another respondent suggested that there had been, and would probably continue to be, a far greater take-up of such products in reinsurance than in direct insurance, mainly because the size of such deals made them more cost effective. (ii) The consensus is that more deals will occur, but that the take-up is likely to be slow. (iii) Most of the reasons mentioned have already been stated in the answers to the third sections of questions 7 and 8, given above. Additional reasons noted included: (a) regulatory and accounting developments; (b) the emergence of specialist niche underwriters who really understand the risks involved; (c) a swing away from the current trend of increasing risk retention by corporates; (d) a move by a significant financial services conglomerate into mainstream corporate insurance; and (e) the occurrence of a high profile case suggesting that enforcement of contractual terms to the detriment of a policyholder was more likely in such deals.

Q10. (i) If you had the responsibility for new product development and marketing in a major insurer/reinsurer or broker, do you feel you should be attempting to develop a suite of 'standard' integrated risk management products? (ii) If so, to what part of the client organisation should the subsequent marketing effort be directed (e.g. CEO, CFO, Treasurer, etc.)? 
A10. (i) Respondents generally considered that it was important to have a product (or template) that was capable of being marketed, but that in practice it needs to be extremely flexible, which was not necessarily easy to achieve. One respondent felt that having powerful and flexible analytical tools was more important than having standardised models per se. Most agreed that understanding customer needs and business drivers was paramount, with different industries likely to have very different priorities. (ii) The natural target of such products was usually regarded as the CFO, other than in companies that had a CRO. While the CFO's time and interest was always difficult to gain, the potential balance sheet and income statement impact of such deals ought to make this a realistic proposition, especially where a contingent capital element was present. For the largest companies, the treasurer might also be a realistic target.

Curiously, and unintentionally, a consensus view of the character of the risk management business and its practitioners gradually emerged as a by-product of the answers to these questions, which may be summed up by three quotations:

"It shows how the risk management profession has failed to rise to the challenge of new forms of risk."

"None of the UK companies with whom I have had dealings during the past decade have ever taken the initiative in seeking from me any information regarding possible deficiencies in that organisation's insurance or risk management programme."

"...the insurance markets have traditionally put barriers between the buyer and seller. This has slowed the development of the market and caused, in part, the low esteem with which it is held." 


\section{Chapter 6}

\section{Conclusions and directions for further research}

\section{Introduction}

In this Chapter we shall recapitulate the main conclusions drawn in the first four Chapters and what appear to be the key responses to the questionnaire summarised in the last Chapter. We shall also suggest some directions for further research.

The Status of Risk Management - Does it Need a Kotler?

In days when major institutions count feng shui experts on their permanent staff, it should not be surprising that risk management practitioners should consider themselves as members of a 'profession', and at that one more broadly defined than the simple insurance from which many of its genes were inherited. Risk management has been around for almost half a century, a period not much different, for example, from marketing and operations research, both of which would generally be regarded as having earned their niches in the pantheon of the professions. Risk management has its gurus, but none as yet has made it to the first rank of management theorists or written the definitive textbook ${ }^{9}$. (It is just possible that Integrated Risk Management by Neil A. Doherty, published by McGraw-Hill, 2000, will eventually fill the latter role - at £45.99 it certainly ought to be at least comprehensive.) Meanwhile, many risk management practitioners need to improve their self-view if they wish society to hold them in more esteem than they sometimes hold themselves.

\footnotetext{
${ }^{9}$ This judgement might be considered harsh in the sense that such luminaries as Robert C. Merton have worked extensively on aspects of financial risk management and written on risk management in a wider context, but they would nonetheless be considered financial economists rather than risk management specialists.
} 
Risk Management and Corporate Finance - A Suitable Case for Treatment

Research has indicated that the absence of insurance from the standard models of corporate finance has held back a coordinated approach to risk management and finance in the corporate environment. That work which has been carried out in this area, for example by Shimpi, P. A. (1999) is not well known and deserves to be promulgated more widely. In an increasingly cost competitive marketplace, where the true value of every dollar spent on insurance may be difficult to assess, this is the one area above all others that would benefit from further theoretical and empirical research.

The Vocabulary of Risk Management - an Impediment to Understanding?

"The United States and the United Kingdom are two countries divided by a common language". That words and phrases have different meanings in different places is not at all unusual; neither is it that different people have different words for the same thing ${ }^{10}$. Even in one place among one group of people language evolves. We should probably not be too hard, therefore, on an internationally dispersed profession that has experienced some difficulty in defining its scope and even greater difficulty in promoting consistent meanings for integrated risk management and enterprise risk management. However, until such times as more discipline is exercised and the use of jargon reduced, practitioners should not be surprised if they are often only imperfectly comprehended. Moreover, the most effective types of communication generally work in two directions and practitioners must also make certain that they have the educational and language skills to understand those with whom they are communicating, who will often have a much broader range of responsibilities than risk management alone. Communications are also rendered less effective by barriers, the erection of which has been something of a specialism of the insurance industry over the years.

\footnotetext{
${ }^{10}$ This is even true in the 'hard' sciences. For example, there was no agreement until recently on the names of the elements with atomic numbers above 103, most of which were first detected as long ago as the 1960 's.
} 
The Place for Risk Management - Just Looking for a Home?

The structure and culture of organisations is sufficiently diverse that there can be no absolutely correct way to organise and control the risk management function. From the literature and response to questionnaires, however, it seems inevitable that board level responsibility for risk in most corporates will be increasingly within the finance function. Nobody expects the CFO or FD to be a master of all trades, but just as it is now bizarre to imagine an accounting qualification not involving at least the key aspects of corporate treasury, it will in future be considered equally absurd to note the absence of at least the key elements of risk management. The sooner this lacuna is dealt with, the higher the probability that the accounting profession can maintain the fortuitous lead in this area it has achieved as a result of its intimate, even incestuous, involvement with Turnbull. Of course, whether or not this is desirable is another question. A formal review of the syllabuses for the principal professional financial qualifications in the UK and the US might make a rewarding research project.

The Chief Risk Officer - Is it a bird, is it a 'plane?

Whilst many financial institutions have found it convenient to appoint a Chief Risk Officer, often with a background in credit risk and/or market risk, such appointments have been much more rare in the corporate sector. There are numerous reasons for this difference in behaviour. The circumstances dominating the financial sector include: greater regulatory emphasis on risk, easier quantitative assessment of key risks, generally higher analytical skills of personnel, more money available for salaries, etc. In the corporate sector one of the key issues is the wide variety of risks faced by the organisation and the difficulty the CRO will have in demonstrating sufficient knowledge of all such risks to be able to add value across the board. When genuine, as opposed to titular, CRO's do begin to be appointed, it will be interesting to review their credentials, which are unlikely to rely heavily on traditional insurance or even traditional risk management. A more probable scenario is that they will have considerable operational experience, possibly with time also spent in a corporate planning and/or corporate finance environment, but certainly possessing the technical skills and vocabulary to negotiate as equals with the financial community with which they will increasingly be dealing directly. Where is Superman when you need him? Although possibly premature for the corporate sector, a comparison of the educational achievements and curricula vitae for Chief Risk Officers in financial institutions might yield some insights. 
The Turnbull Guidelines - an Interim Assessment

The authors of the Turnbull Guidelines would probably be satisfied if the consensus opinion of their work was that it could be described as a 'flawed masterpiece'. In reality, only one of these words was encountered during the research for this dissertation and, regrettably, it was not 'masterpiece'. Turnbull was conceived as a set of guidelines on internal controls. During its gestation it transmuted into a pot-pourri, including a prayer for a new philosophy of risk management. It cannot be surprising that it has been poorly received thus far and it will not be surprising in future if it is relatively quickly supplanted by something more focused and relevant, produced by a body with a more balanced view than the ICAEW. The question of Turnbull's 'lack of teeth' was mentioned by some questionnaire respondents ${ }^{11}$, but a similar criticism has been levied at the Combined Code generally and the consensus seems to be that it is too soon to determine whether stricter sanctions need to be contemplated seriously. Internationally, there seems to be a case for aligning corporate governance regulations, as is already the case with accounting standards, and this is another area that could provide interesting research opportunities. While the Turnbull authors may have reviewed the work of the Treadway Commission (COSO) and of the Dey Committee, this is not readily apparent.

\section{Risk Management and Accounting Standards - Non-consenting Adults}

There is little doubt that in the United States the introduction of FASB 133, requiring the marking to market of all derivatives products (defined very broadly) has acted as a brake on the development and utilisation of products that seek to integrate the management of insurable and financial risks. While full disclosure of derivatives positions is generally considered to be beneficial to both large and small investors, the income statement impact of marking to market is not. The increase in the volatility of earnings resulting from the implementation of this accounting standard has caused a groundswell of antagonism towards FASB by both corporates and financial institutions; the chances are that at some time over the next five years the application of the marking to market rule will be relaxed ${ }^{12}$. The indirect impact of FASB 133 on UK companies with US listings has been noted and it is to be hoped that the UK accounting standards body does not make the same mistakes as its US counterpart.

\footnotetext{
${ }^{11}$ Essentially, companies not complying have to state in their Annual Report that they have not done so and why.

${ }^{12}$ The precedent for this is the introduction of FASB 22, which modified FASB 8, the original standard on accounting for foreign exchange hedges.
} 
Enterprise Risk Management - Hula Hoop or Cellphone?

Notwithstanding the considerable shortcomings of Turnbull, the intellectual and regulatory cases for enterprise risk management are individually persuasive and together compelling. Like the early cellphones that were regarded as trendy, unnecessary and expensive, there is still a body of thought that believes enterprise risk management will not become a permanent addition to the executive's repertoire of valid approaches to strategic management. This is almost certainly a mistake. The present enterprise risk management edifice may shrink in size, like the cellphone, but it is unlikely to be as ephemeral as the hula-hoop.

Integrated Risk Management - The Six Million Dollar Solution?

Some readers may be old enough to remember the phrase "We have the technology, we can rebuild him ...", which for many years introduced the weekly television series The Six Million Dollar Man. The premise that the technology existed and only awaited the arrival of a suitable opportunity for its application might today be directed towards integrated risk management. However, this technology may be less perfect than some of its proponents would prefer to admit (or inadequately mastered by them) and those areas where it has been applied successfully have tended to involve incremental advances rather than the 'quantum leaps' necessary for successful TV. Risk solutions that push forward the limits of insurability seem to be market driven and thus successful. Those that integrate for integration's sake, as may have been the case with Honeywell, often have a precarious existence.

\section{Demand for Integrated Risk Management Products - Price Elasticity Factors}

The literature would suggest that one of the determinants for the relatively slow take-up of multi-year, multi-line programmes is the prolonged 'soft market' that has obtained since their theoretical attractions began to be better appreciated. This view was also supported by the questionnaire responses. However, there is almost no discussion in the literature of the fundamental difference between the relative methods of premium pricing for insurance products and financial derivatives. Whereas various sophisticated models (e.g. Black-Scholes and its variants) provide a high degree of objectivity in the pricing of derivatives (only volatility usually being a subjective input), this is certainly not the case for insurance products. For example, it has 
been suggested that macro economic factors, such as interest rates and stock-market levels have a strong, but not easily quantifiable, impact on premium levels, as well as loss experience. One result of this is that the phenomenon of cyclicality, frequently observed in many insurance markets, is unknown in derivatives markets. The corollary is that even if a prolonged 'hard market' has a positive impact on the use of integrated insurance products, it is unlikely to have a dramatic impact on the use of combined insurance/financial risk products. A prolonged hard market might, however, encourage the development of more sophisticated budgetary and accounting models dealing with the allocation of insurance costs and benefits, thereby obviating one of the other problems identified in the slow take-up of integrated products. Although data specifically on integrated risk products might be hard to obtain, if available it could be used to extend the research already in progress at City University Business School by Professor Gerry Dickinson on the insurance cycle.

\section{The Major Insurance Providers - Behind the Banks or the Eight Ball?}

One of the commonest criticisms encountered of purveyors of integrated risk management products, whether brokers or insurers, has been their failure to communicate adequately the benefits of their wares. A number of factors seem to be involved, not least the separate and rapid evolutions of the insurance broking and underwriting sectors and the corporate risk management function. However, the evolution of the banking sector has been at least as rapid over the last decade and a similar criticism has not often been heard in respect of those selling 'sophisticated' banking products. On the basis of anecdotal evidence only, it seems possible that the early adoption by the banking sector of well-trained account executives in a position to understand effectively all of the needs of the Finance Directors and Treasurers may have made the difference. Typically this has not been the pattern adopted in the insurance sector, where product specialists have often not been in a good position to grasp the overall needs of the client and to see opportunities for growth and innovation. While some firms seem to have made progress in this area, often by means of better training and recruiting more highly qualified staff, much remains to be done in terms of restructuring the insurance/broking/corporate interfaces, particularly in terms of training in general financial skills (including corporate finance) and basic communications. If the insurance providers do not follow this path, they risk the capital markets partners, with whom they are working increasingly on some types of deal, usurping the lead role that many would believe to be rightfully theirs. Another relevant factor is that where mergers have occurred between major banks and commercial lines insurers, real cultural differences seem to have impeded the generation 
of the synergies that might have been expected in the area of integrated risk management. This point is examined further below.

Life in the New Markets' Jungle - Nasty, Brutish and Short?

It is far from clear who will emerge at the top of the integrated risk management food chain. Consolidation in the insurance sector has not only seen fewer firms (e.g. the formation of CGNU from Commercial Union, General Accident and Norwich Union), but also the subsequent withdrawal of the merged firms from global risk management (e.g. CGNU and R\&SA). The 'super-group' bancassurance mergers (e.g. Citicorp/Travelers and Credit Suisse/Winthertur) do not seem to have been orchestrated with these particular synergies in mind. In fact, as this Chapter is being drafted, an even more significant indictment of firms' inabilities to capitalise on such associations is underway, with the Axa majority shareholding in Donaldson, Lufkin \& Jenrette in the process of being sold, ironically, to Credit Suisse First Boston, the investment banking division of Credit Suisse. The resource being devoted to this area by some of the major reinsurance industry players (e.g. Swiss Re New Markets and Zurich Re/Centre Solutions) is considerable and reflects the relatively favourable character of the reinsurance (as opposed to direct insurance) marketplace, but neither of these groups would generally be considered expert in capital markets. For the time being, at least, the buy side of the capital markets seems myopically focused on bonds to the detriment of potentially more effective and thus, ultimately, more rewarding risk transfer products (e.g. contingent capital). The sell side of the capital markets has the capacity to succeed if it wishes to do so (e.g. Goldman Sachs), but presently does not seem to be deploying its resources to their full extent. However, the status quo will not be preserved and the 'hot money' has to be on the investment banks, mainly because they have the capacity to pay the highest salaries and attract the best staff should they wish to do so. This may be on the basis of informal or even formal alliances with insurers, but it is not beyond the bounds of possibility that, for example, a Swiss Re may end up owning a Merrill Lynch (which could also make sense from a funds management perspective). 


\section{Conclusion}

Risk is usually poorly taught at whatever level of the educational system one chooses to examine: classes at primary and secondary school, undergraduate and postgraduate lectures at university and courses for professional examinations. Unlike return, of which most people have an innate understanding, the concept of risk is largely alien and this has not been redressed by the development of appropriate teaching methods ${ }^{13}$. This situation is unlikely to change in the short term. However, risk and return are intimately related and, periodically, the occurrence of a large enough risk event will impact the returns enjoyed by investors on their investments, savings or pensions. Such circumstances have encouraged a mood in investor circles that 'somebody ought to do something about it'. While the heavy hand of government regulation has always been present to some degree, its failure to exercise its proper responsibilities ${ }^{14}$ has led to the development of an alternative approach, one example of which is the Turnbull Guidelines, with all of its imperfections. However, one way or another, companies are having to think more about the risks faced by their businesses, creating a demand for products and services that facilitate this. Meanwhile, the search for value continues, which should also ultimately help to provide a receptive audience to providers of integrated risk management products. The steady convergence of the capital and insurance markets and the partnerships thereby developing should ensure that at least some product providers have the intellectual and communications skills necessary to take advantage of increasingly favourable circumstances. Product buyers are simultaneously finding themselves in a position where they have to take a broader view and acquire the additional skills needed to perform well in expanding roles. Thinking about risk management is changing quite dramatically and quite quickly. Dramatic changes in risk management practices will be encompassed more slowly and may never achieve the levels imagined by some, but they will occur.

${ }^{13}$ See, for example, "Take a chance" (New Scientist, $12^{\text {th }}$ August 2000).

${ }^{14}$ For example, as epitomised by the Bank of England's acknowledged and disgraceful lack of proper supervision of Johnson Matthey Bank, BCCI and Barings, thus contributing to the ensuing scandals and resulting in the transfer of banking supervision to the FSA. 


\section{Appendix}

\section{Questionnaire used in research}

\section{Introduction}

The purpose of this questionnaire is to elicit the opinions of 8 to 10 leading risk management practitioners in connection with the state of play of the Enterprise Risk Management approach and Integrated Risk Management products, with particular emphasis on the UK. Participating companies who give their permission will be identified in the dissertation and any resulting papers or articles. However, specific responses to individual questions will not be attributed to participants.

\section{Details of Responding Organisation}

Name of company:

Name of individual:

Position of individual:

E-mail address of individual:

I am prepared for the participation of my organisation in this survey to be disclosed, but not my responses to individual questions or to any overall characterisation of my organisation's view.

YES / NO (Please delete as necessary)

I would like to receive an electronic copy of the completed dissertation on Integrated Risk Management, which should be available in September 2000, at no charge ${ }^{15}$.

YES / NO

(Please delete as necessary)

Signature of individual:

Date:

15 Bound copies will be available at cost to any respondent interested in receiving one. 


\section{Section I - Turnbull}

\section{Question 1}

The Turnbull Guidelines on internal controls arising out of the Combined Code require UK listed companies to adopt a systematic approach to risk management in its widest sense, what might be called Firm-Wide or Enterprise Risk Management. Do you believe that the implications of Turnbull have yet been fully appreciated by UK listed companies?

\section{Question 2}

Some companies, of course, already approach risk management in a broad and structured manner. Do you foresee that those that do not will change their approach fundamentally, or are they more likely to do the minimum necessary to achieve the tick of their auditors?

\section{Question 3}

Do you have any views on the fact that the drawing up of the guidelines was delegated to the accountancy profession?

\section{Question 4}

As CEO of a traditionally organised major UK plc, to whom within your organisation would you give principal responsibility for ensuring compliance with Turnbull?

\section{Question 5}

Do you have any other strong views on Turnbull?

\section{Section II - Integrated Risk}

\section{Question 6}

Various tools, mostly bespoke, have been developed for the integrated management of insurable 
and financial risks, for example 'double trigger' insurance policies. Do you feel that Turnbull in the UK, and similar regulations elsewhere, will have a significant positive influence on the speed of development and acceptance of such products?

\section{Question 7}

The literature would suggest an upsurge of interest in multi-line, multi-year insurance products. (i) Do you believe that there has been higher than average premium growth from such products over the last five years? (ii) Do you believe that there will be higher than average premium growth from such products over the next five years? (iii) What factors could make you wrong about your forecast?

\section{Question 8}

Multi-line financial risk management products have also become more common over the last five years, albeit probably to a lesser extent. (i) Do you believe that there has been higher than average income growth from such products over the last five years? (ii) Do you believe that there will be higher than average income growth from such products over the next five years? (iii) What factors could make you wrong about your forecast?

\section{Question 9}

True integrated insurable/financial risk management deals, e.g. Honeywell, have so far been relatively few and far between. (i) Given that the technology has existed for over a decade, why do you feel this is? (ii) Do you feel there is likely to be an acceleration in growth over the next decade. (iii) What factors could make you wrong about your forecast?

\section{Question 10}

If you had the responsibility for new product development and marketing in a major insurer/reinsurer or broker, do you feel you should be attempting to develop a suite of 'standard' integrated risk management products? If so, to what part of the client organisation should the subsequent marketing effort be directed (e.g. CEO, CFO, Treasurer, etc.)? 


\section{Glossary}

\section{Introduction}

This glossary covers not only terms and phrases related specifically to integrated and enterprise risk management, but also to terms encountered in a more general risk management context. In each case a word or phrase has been given its most widely accepted insurance or risk management meaning; where two or more meanings are common, both are given. It has been compiled from a wide variety of sources, including: ABI (1998); Aon (1999); Diacon, S. R. and Carter, R. L. (1992); Hull, J. C. (2000); Rubin, H. W. (2000); Shimpi, P. A. (1999); Swiss Re (1996); and Swiss Re (1998).

Accumulation A collection of losses arising from a single event or catastrophe.

Acquisition costs The costs of soliciting and placing insurance business, including commissions.

Alternative risk transfer ("ART") (1) Narrowly, methods of transferring risks to a third party other than by using a conventional insurance policy, e.g. by Risk securitisation, Catastrophe derivatives or Contingent capital. (2) Broadly, all 'non-traditional' means of approaching the risk financing process, including Self insurance (through a Deductible, Excess, or Captive), Risk retention groups, ART as narrowly defined, Finite risk, etc.

Attachment point For any excess policy, the level of claims at which the policy comes into effect, usually the maximum cover under the primary policy. Multiple attachment points will exist if there is more than one Excess layer.

Bifurcation The disaggregation of an insurance transaction into two components (e.g. for purposes of determining the tax treatment). An example would be a transaction that involved a 'finite' (i.e. non-risk transfer component), for which the premiums would not generally be tax deductible, and a true risk transfer component, for which the premiums would generally be tax deductible.

Capital Generally, Shareholders' funds, but often calculated on a specific basis or subject to specific adjustments depending on the context (e.g. less the Embedded value of any life business 
and plus the value of any Subordinated debt).

Captive (insurance company) A company, usually wholly owned, formed by its parent to insure some or all of the risks of its parent.

Catastrophe derivative A Derivative for which the underlying 'asset' is a defined catastrophic loss experience, a form of ART.

\section{Commercial risks See Strategic risks.}

Contingent capital Capital, sometimes debt, but more often some form of equity, which may be called by a company on defined terms in the event of stated catastrophes occurring.

Convergence (1) The coming together of the insurance and capital markets as a result of liberalisation and deregulation. (2) The management of risks using a combination of insurance market and capital market products.

Credit derivative A Derivative for which the underlying 'asset' is a credit default event, a form of ART.

Deductible The initial amount of every loss that must be paid by the insured.

Deferred acquisition costs An asset representing acquisition costs for business at least part of which relates to a financial year other than that in which such costs were incurred. They are written off over the expected life of the business, which can be more than one year in case of genuinely long term business and short term business that is expected to renew. Sometimes netted off against Unearned premium reserve.

Derivative A security (i.e. financial instrument) for which the price is derived by reference to that of some underlying asset or liability.

Double trigger An insurance policy that pays out only when two events have occurred, for example property losses in a given year exceed one level and foreign currency losses exceed some other level. 
Equalisation reserve Reserve set up by an insurer which can be credited or debited if the total claims received in a given year are, respectively, lesser or greater than would on average be expected.

Embedded value The present value of any insurance business based on policies presently in place attributable to the shareholders of that business, as opposed to the policyholders; often applied to life business.

Enterprise risks The total body of risks facing an enterprise, comprising Financial risks, Insurable risks and Operational risks.

Enterprise risk management The management of all the risks facing an enterprise on a comprehensive and holistic basis.

\section{Enterprise-wide risk management See Enterprise risk management.}

\section{Excess See Deductible.}

Excess layer A layer of cover above the Primary layer for which the risk is borne by the insured or another insurer.

Financial reinsurance (1) Originally, reinsurance where no underwriting, timing or interest rate risk passed from the insurer to the reinsurer, arranged solely to effect the discounting of liabilities for solvency testing purposes. (2) Today, policies where some element of underwriting and/or timing risk is transferred, but the principal effect is till the discounting of liabilities.

Financial risks Those risks resulting from exposure to movements in the prices of financial assets and liabilities, for example: foreign exchange rates, interest rates, commodity prices, etc. See also Speculative risks.

Finite risk reinsurance Multi-year and, usually, multi-line policies allowing insurers to benefit from passing on a pool of risks rather than a single risk to a reinsurer, thus benefiting from a lower total coverage requirement and hence lower premiums.

Firm-wide risk management See Enterprise risk management. 
Free reserves (1) See Shareholders' funds. (2) The excess of actual Capital calculated for regulatory purposes less the minimum Capital required for regulatory purposes.

Friction On average, a dollar spent on insurance will not be rewarded by a dollar received in claims, due to the overhead recovery and profit requirement of the insurance company; this phenomenon is often referred to as friction and the difference between the two amounts as frictional losses.

Gross As applied to a reserve, premium, etc, the amount before deduction of any off-setting reinsurance reserve, premium, etc.

Holistic risk management See Enterprise risk management.

Incurred but not reported (reserve) ("IBNR") Funds put aside by an insurer in respect of claims that have been estimated on the basis of an appropriate model, but which have not yet been reported.

Insurable risks Those risks where there is only a possibility of loss. Contrast with Speculative risks.

Integrated risk management (1) See Enterprise risk management. (2) More narrowly, the management of financial and insurable risks on an integrated basis.

Limit The maximum amount that an insurer is prepared to lose on an average risk of a particular class.

Movements in shareholders funds Reconciliation between opening and closing Shareholders' funds in an insurance company's accounts, including such items as profit for the year, dividends, etc.

Net As applied to a reserve, premium, etc., the amount after deduction of any off-setting reinsurance reserve, premium, etc.

New markets Depending on the context, this may be a reference to Alternative Risk Transfer or Integrated Risk Management. 
Non-technical account That portion of an insurance company's profit and loss account dealing with items not directly attributable to the life business or the non-life business, e.g. investment income on shareholders' funds not attributable to the life or non-life business.

Operational risks These are the risks that cannot be hedged by traditional risk transfer techniques, financial and insurance derivatives, or ART.

Outstanding claims reserve Funds put aside by insurance companies to cover claims that have been incurred and reported, but not yet paid.

Package deals These are combined programmes, particularly popular in the United States, that are designed to be of interest to a particular industry, e.g. trucking, utilities or retail. Although they may be written as a single policy, they almost invariably involve different limits for different risks and are thus not truly integrated products. They attract discounts by virtue of the size of the combined premium involved, not because of the combination of risks.

Policyholders' funds Funds set aside by an insurer to cover outstanding liabilities of policyholders, including Unearned premium reserve, Unexpired risk reserve, Outstanding claims reserve, IBNR, etc.

Primary layer The basic layer of cover under an insurance policy up to the limit of which claims will be paid, less any Deductible.

Reinstatement In some cases an insured may be able to reinstate a Limit that has been fully utilised by the payment of an additional premium.

Retrospective rating plan ("retro") A plan where the premium payable, normally with pre-agreed upper and lower limits, is based on the actual loss experience over the life of the plan (usually several years).

Risk assessment The identification of risks in terms of their probable frequency and severity.

Risk control The adoption of a prudent response to risks, such as avoidance, prevention, reduction, sharing, contingency planning, etc. 
Risk financing The provision of sufficient funds through self insurance, third party risk transfer or access to contingent capital for a company to maintain its obligations to stakeholders when losses occur.

Risk identification The process of identifying possible events or activities that could cause or enhance losses.

Risk management The programme of identifying, measuring and controlling risk.

Risk measurement The assessment of the impact of possible losses.

Risk retention group Essentially, a Captive owned by a number of parents providing cover in respect of particular risks that would otherwise be difficult to obtain in the market place or at a comparable cost.

Risk securitisation A form of ART in which the return on a security, usually a bond, is tied to the performance of an underlying pool of risk or a single risk event (e.g. an earthquake of given magnitude in a defined area).

\section{Securitisation See Risk securitisation.}

Self insurance Risk retention on either a funded (e.g. through a Captive) or unfunded basis.

Senior debt Debt for which repayment of principal and interest ranks before the payment of policyholders' claims in the event of a liquidation. Never included in capital for regulatory purposes, but may be for management purposes.

Shareholders' funds Funds of an insurance company not tied to liabilities to policyholders or other parties (e.g. lenders).

Speculative risks Those risks where there is a possibility of gain as well as loss, for example most types of Financial risks.

Statement of total gains and losses That portion of an insurance company's profit and loss 
account dealing with all items not appropriate to be included in the technical or non-technical accounts, e.g. movements in the embedded value of a life subsidiary, currency translation gains and losses relating to overseas subsidiaries and associates, etc.

\section{Strategic risks See Enterprise risks.}

Subordinated debt Debt for which repayment of principal and interest ranks after the payment of policyholders' claims in the event of a liquidation. Sometimes included in capital for regulatory purposes (in whole or in part), but may be for management purposes.

Technical account That portion of an insurance company's profit and loss account dealing with the income and expense of the life business (the life technical account) or the non-life business (the non-life technical account).

\section{Technical reserves See Policyholders' funds.}

Time and distance policies See Financial reinsurance (1).

\section{Total risk management See Enterprise risk management.}

Unbundling The separation of the different elements of a traditional insurance policy, for example claims handling and risk financing.

Unearned premium reserve Funds set aside by the insurer from premiums received to cover potential liabilities on policies still in force at the end of the year.

Unexpired risk reserve Funds set aside by an insurer to cover potential liabilities on policies still in force where estimated claims are in excess of those represented by any Unearned premium reserve.

Value at risk ("VAR") is an attempt to provide a single number summarising the total risk in a portfolio of financial assets. A VAR statement is typically of the following form: "We are X per cent certain that we will not lose more than $\mathrm{Y}$ dollars in the next $\mathrm{N}$ days". VAR is used by regulators to determine the minimum amount of capital (some multiple of $Y$, perhaps 3 ) required by a bank undertaking trading operations, in which case $\mathrm{N}$ is normally 10 days and $\mathrm{X}$ is $99 \%$. 


\section{Table of References}

ABI (1998). Statement of recommended practice: accounting for insurance business. The Association of British Insurers, December 1998.

ACT (2000). Why ART? ACT Manual of Corporate Finance and Treasury Management Bulletin, Gee, London, Issue 1, April 2000.

AIRMIC (1999). Integrated Risk Management. The Association of Insurance and Risk Managers, 1999.

Ash, James et al (1999). Enterprise Risk Management. Comprising Editions 3 and 41999 of Insights, Aon Risk Services.

Banham, Russ (1999). The final frontier of risk. Reactions, 19 (5) May 1999, pp 20-22.

Banham, Russ (2000). Rethinking the future. Reactions, 20 (4) April 2000, pp 18-20.

Bannister, James E. (1998). Alternative risk financing: changing the face of insurance. Jim Bannister Developments Limited with Aon Group and Zurich International, 1998.

Bannister, James E. and Bawcutt, Paul A. (1981). Practical risk management. Witherby \& Co., London, 1981.

Barnett, Jonathan and Meulbrook, Lisa (2000). Honeywell, Inc. and integrated risk management. Harvard Business School Case Study, reference N9-200-036.

Bear, Keith (1999). Reinventing firm-wide risk management. Enterprise Risk Management Supplement to Risk Magazine, 12 (11) November 1999, pp 16-17.

Berry, Andrew and Phillips, Julian (1998). Enterprise risk management: pulling it together. Risk Management, September 1998.

Integrated Risk Management - Page 73 
Brandman, James (1999). How to guarantee your earnings. Reactions, 19 (4) April 1999, pp 24-27.

Brosnan, Michael (1998). United we stand. Enterprise Risk Management Supplement to Risk Magazine, 11 (11) November 1998, pp 12-14.

Bugalla, John A. (2000). Enterprise risk management - is it for you? Treasury Management International, January 2000, pp 39-41.

Cadbury, Sir Adrian [chairman] (1992). Report of the Committee on Financial Aspects of Corporate Governance. Gee Publishing, December 1992. ("The Cadbury Report")

CIBC Wood Gundy (1997). Firm-wide risk: how firms are integrating risk management. Risk Magazine, 10 (3) March 1997.

Crockford, Neil (1980). An introduction to risk management. Woodhead-Faulkner, Cambridge, 1980.

Davies, Peter and Reichenberg, Eric (1998). Expanding the frontiers of enterprise risk management. Enterprise Risk Management Supplement to Risk Magazine, 11 (11) November 1998, pp 6-8.

Dehnad, Kosrow (1996). Hedging in Harmony, AsiaRisk, November 1996.

Dey, Peter [chairman] (1994). Report of the Toronto Stock Exchange Committee on Corporate Governance: "Where were the directors?". Toronto Stock Exchange, December 1994. ("The Dey Committee")

Dey, Peter [chairman] (2000). Report of the Toronto Stock Exchange Committee on Corporate Governance: the state of governance in Canada. Toronto Stock Exchange, July 2000.

Diacon, S. R. and Carter, R. L. (1999). Success in Insurance. John Murray, London, $3^{\text {rd }}$ ed. 
1992.

Dickinson, Gerrard M. (1997). Integrating insurance and hedging decisions into the overall risk management of the firm. Singapore International Insurance and Actuarial Journal, Inaugural Issue October 1997, 1 (1), 161-173.

Dickinson, Gerrard M. (1998). The economic role of the insurance sector in the risk transfer capital market nexus. Geneva Papers on Risk and Insurance, October 199823 (89), 519-529.

Dickinson, Gerrard M. and Dinenis, Elias (1993). The changing strategic interface between insurance and banking. Geneva Association Conference Proceedings, Erasmus University, Rotterdam, 1993.

Doherty, Neil A. (1985). Corporate Risk Management, McGraw Hill, 1985.

Doherty, Neil A. and Smith, Clifford W., Jr (1994). Corporate insurance strategy: the case of British Petroleum. Journal of Applied Corporate Finance, 1994, 4-15.

Falloon, William (1999). Reliance first with earnings protection. Risk Magazine, 12 (5) May 1999.

Gardner, Mona J. and Mills, Dixie L. (1994). Managing financial institutions: an asset-liability approach, The Dryden Press, Fort Worth, Texas, 1994.

Goldman Sachs and SBC Warburg Dillon Reed (1998). A framework for firm-wide risk management. Chapter 3 in "The Practice of Risk Management", Euromoney Publications, 1998, $29-43$.

Greenbury, Sir Richard [chairman] (1995). Report of the Study Group on Directors' Remuneration. HMSO, 1995. ("The Greenbury Report")

Haimes, Yacov Y. (1989). Towards a holistic approach to risk assessment and management. Risk Analysis, June 19899 (2). 
Haimes, Yacov Y. (1991). Total risk management. Risk Analysis, June 199111 (2).

Haimes, Yacov Y. (1992). Towards a holistic approach to total risk management. Geneva Papers on Risk and Insurance, July 199217 (64), 314-321.

Hampel, Sir Ronald [chairman] (1998a). Report of the Committee on Corporate Governance. Gee Publishing, January 1998. ("The Hampel Report")

Hampel, Sir Ronald [chairman] (1998b). Combined Code of the Committee on Corporate Governance. Gee Publishing, June 1998. ("The Combined Code")

Harris-Jones, Judith and Bergin, Louise (1998). The management of corporate risk: a framework for directors, The Association of Corporate Treasurers, 1998.

Helbling, Carolyn P., Falleger, Georg, and Hill, Donna (1996). Rethinking risk financing. Swiss Reinsurance Company, Zurich, 1996.

Hiscock, Jane. (1999). Managing and controlling buy and sell side risk. Enterprise Risk Management Supplement to Risk Magazine, 12 (11) November 1999, pp 9-10.

Hersberger, Willy (1996). Insurance and risk capital: Swiss Re's value proposition. Swiss Reinsurance Company, Zurich, 1996.

Hull, John C. (2000). Options, Futures and Other Derivatives. $4^{\text {th }}$ ed. Prentice-Hall, New Jersey, 2000 .

Kloman, H. Felix. (1990). Risk management agonistes. Risk Analysis, June 198910 (2).

Kloman, H. Felix (1992). Rethinking risk management. Geneva Papers on Risk and Insurance, July 199217 (64), 299-313.

Kloman, H. Felix. (2000). Understanding the new mantra. Reactions, April 200020 (4), pp 
$22-23$.

Mehr, Robert I. And Hedges, Bob A. (1963). Risk management in the business enterprise. Irwin, Homewood, Illinois, 1963.

Merton, Robert C. (1999). Finance theory and future trends: the shift to integration. Risk Magazine, 12 (7) July 1999.

Punter, Alan (2000). New solutions for the financing of risk. Insurance Research and Practice, 15 (2) July 2000, pp 29-40.

Rahadjo, Kay and Dowling, Mary Ann (1998). Strategic risk management: a broader vision. Risk Management, September 1998.

Raschewski, Thomas (1999). Taking blended risk financing methods from theory to cutting edge solutions. Global Insurance Bulletin, July 1999, pp18-22.

Richardson, Gregory J. (1999). Convergence and enterprise risk management. The Risk Financier, 3 (6) June 1999, pp 3-4.

Ross, Derek A. (1997). Strategic risk management for financial institutions, CTA Financial Publishing, London, 1997.

Rubin, Harvey W. (2000). Dictionary of insurance terms, Barron's, $4^{\text {th }}$ ed. 2000.

Sanderson, Scott M. (1997). Combining hazard and financial risk: the next challenge for the risk manager? Canadian Treasurer, July 1997.

Sanderson, Scott M. (1999). Comparative efficiency of capital and insurance markets in managing risk. Financing Risk and Insurance, March 1999.

Sanderson, Scott M. and Koritzinsky, Arthur G. (1999). Risk centres. Risk Management, March 1999. 
Schön, Elisabeth, Boccichio, Vincenzo and Wolfram, Edith (1998). Integrated risk management solutions - beyond traditional insurance and financial hedging. Swiss Reinsurance Company, Zurich, 1998.

Shimpi, Prakash A. (1997). The context for trading insurance risks. Geneva Papers on Risk and Insurance, January 1997, 22 (82) 17-25.

Shimpi, Prakash A. ed. (1999). Integrating corporate risk management. Swiss Reinsurance Company, Zurich, 1999.

Smith, Clifford W. (1995). Corporate risk management: theory and practice. Journal of Derivatives, Summer 1995, 21-30.

Strutt, Rodney S. G. et al (1991). A definitive technique for risk assessment? Paper to first Institute of Risk Management Conference, London, 1991.

Swiss Re (1996). An introduction to reinsurance. Swiss Reinsurance Company, Zurich, 1996.

Swiss Re (1998). Questions of reinsurance: a short guide. Swiss Reinsurance Company, Zurich, 1998.

Thornhill, Wil and Derksen, Amy (1998). A united approach: creating integrated risk plans. Risk Management, August 1998.

Treadway, James C., jr. [chairman] (1991). Report of the Committee of Sponsoring Organisations of the Treadway Commission: Internal Control - Integrated Framework. ("COSO " or "The Treadway Commission")

Turnbull, Nigel [chairman] (1999). Internal control: guidance for directors on the Combined Code. The Institute of Chartered Accountants in England and Wales, September 1999. ("The Turnbull Guidelines")

Wood, Justin (2000). Risk Nirvana. CFO Europe, February 2000, pp 42-48. 


\section{Note on Other Sources}

During the last few years many newspapers and magazines have run supplements entirely or significantly focused on enterprise and integrated risk management. Among those that have been referred to in the preparation of this dissertation are: Risk Magazine, Supplements to the issues of November 1997 (sponsored by KPMG), November 1998 (sponsored by Askari and BARRA) and November 1999 (sponsored by PricewaterhouseCoopers and BARRA). Also, several of the articles appearing in the Weekly Supplements to the Financial Times for the issues of Tuesday April $25^{\text {th }}$ to Tuesday June $27^{\text {th }}$ ('Mastering Risk', sponsored by Arthur Andersen and Aon) touch on integrated or enterprise risk management, for example "Total strategies for company-wide risk control" by Lisa Meulbrook on $9^{\text {th }}$ May 2000. 


\section{Supplement}

\section{Completed Questionnaires from Respondents}

Company

Aon Group Limited

Chase

Citigroup

Deloitte \& Touche

Marsh 91

McKinsey 94

PricewaterhouseCoopers 96

Prudential Group plc 99

Swiss Re.

TRW Inc.

United Insurance Brokers - I

United Insurance Brokers - II

Willis 


\section{Details of Responding Organisation}

Name of company:

Name of individual:

Position of individual:

E-mail address of individual:
Aon Group Limited

Alan Punter

Chairman's Office

alan.punter@aon.co.uk

I am prepared for the participation of my organisation in this survey to be disclosed, but not my responses to individual questions or to any overall characterisation of my organisation's view.

YES

(Please delete as necessary)

I would like to receive an electronic copy of the completed dissertation on Integrated Risk Management, which should be available in September 2000, at no charge.

YES

(Please delete as necessary)

Signature of individual:

JWH pp AP

Date:

$06 / 08 / 00$

\section{Section I - Turnbull}

\section{Answer 1}

Turnbull implications as stated have been largely appreciated, but $[\mathrm{I}]$ regard the requirements of Turnbull to be rather weak and unspecific.

\section{Answer 2}

[The latter]. [I] view Turnbull as a compliance activity, making little change as to how companies monitor or manage risk.

\section{Answer 3}

[It] may explain why much of business risk, particularly those exposures typically addressed by 
insurance and related risk management and risk financing are hardly mentioned ${ }^{16}$. Insurance is the ? subject.

\section{Answer 4}

Because of the foregoing [it] has to be the CFO/FD.

\section{Answer 5}

Following on from (1) and (3) above, I do not believe Turnbull really addresses risk in an Enterprise of Firm-Wide basis - [and] does not give enough guidance on the range of risks to be covered or how risk management is to be implemented.

\section{Section II - Integrated Risk}

\section{Answer 6}

Little or no impact because of (3) and (5) above.

\section{Answer 7}

(i) More than average interest; slightly more than average premium growth.

(ii) Yes, but mainly due to hardening in primary insurance rates (rather than Turnbull).

(iii) Failure of insurance markets to harden efficiently to regain profitability and remain viable.

\section{Answer 8}

No knowledge of developments in purely financial risks.

\section{Answer 9}

- Internal 'silos' between insurance and treasury departments - lack of communications, different attitudes to measurement and management of risk, jargon barriers, how to allocate premium costs and any benefits between departmental budgets, lack of knowledge by broker account executives.

- Financial risks may be included in multi-line insurances, but more as an incidental, relatively minor risk - not truly 50/50 insurable/financial risks.

- A move by a significant financial services conglomerate into mainstream corporate insurances.

\section{Answer10}

(i) Yes - basic, template products, from which to develop and craft solutions, since [they] have to be customised. More important to understand client needs and drivers and work back to product development. (ii) $\mathrm{CFO}$, on basis that [responsibility] straddles insurance and treasury type risks and needs to be presented incorporate finance framework (which is where we started talking!).

\footnotetext{
${ }^{16}$ I believe that accounting qualifications do not mention risk and insurance. [The] LSE MSc in Finance hardly mentions insurance.
} 


\section{Details of Responding Organisation}

Name of company:

Name of individual:

Position of individual:

E-mail address of individual:
Chase

Paul Shotton

M.D. Head of Market Risk Management EAME

paul.shotton@chase.com

I am prepared for the participation of my organisation in this survey to be disclosed, but not my responses to individual questions or to any overall characterisation of my organisation's view.

NO

(Please delete as necessary)

I would like to receive an electronic copy of the completed dissertation on Integrated Risk Management, which should be available in September 2000, at no charge.

YES

(Please delete as necessary)

Signature of individual:

JWH pp PS

Date:

$24 / 08 / 00$

\section{Section I - Turnbull}

\section{Answer 1}

Understanding of sound risk management practice is far more widespread now than was the case a few years ago, but I would doubt that all implications have been appreciated. Banks, as a result of regulatory scrutiny, particularly by the FSA, which as a new regulator has been keen to establish a strong reputation, are generally well-advanced in this regard.

\section{Answer 2}

They will do the minimum possible, until something goes seriously awry. Then, if they are lucky enough to survive it, they will be jolted into taking action and making the necessary fundamental changes.

\section{Answer 3}


Obviously accountants, through their management consultancy arms, have an axe to grind in this regard. As one might expect, the tailored solutions they peddle demonstrate their expertise in exchanging money for old rope.

\section{Answer 4}

I would have a director responsible for risk management reporting directly to me as CEO. This role could be split between responsibility for risk management and for finance, but I would not have the Head of Risk Management reporting into the CFO. The Head of Risk Management should be co-equal with the CFO, either two separate people reporting to me, or one person with co-equal responsibilities.

\section{Answer 5}

Generally sound principles which any right-thinking organisation would want to adopt.

\section{Section II - Integrated Risk}

\section{Answer 6}

No, such instruments will take a long time to become acceptable in the fairly conservative UK environment, except amongst the most sophisticated organizations.

\section{Answer 7}

I do not have direct knowledge of the use of these instruments to enable me to make a valid comment.

\section{Answer 8}

Such products have been a high-growth area for some of the largest institutions in recent years, but I anticipate a slow-down, which I believe has already started, as these products become commoditised. Ability to trade and distribute these instruments via the Internet may increase growth as distribution channels are increased, but I expect this effect to be offset by the increased effect which these channels will have on commoditisation.

\section{Answer 9}

Conservatism and a reluctance to embrace what are sometimes quite complex financial concepts by senior management. An acceleration is likely as these ideas do become more widespread and competition increases pressures on management to perform financially. This would be slowed, however, if there arose legal complications on enforcement of contractual terms in a high-profile case.

\section{Answer 10}

The ability to produce both standard and tailored products would be necessary. CFO is best person to target, as sufficient expertise in understanding products is necessary to get buy-in. 


\section{Details of Responding Organisation}

Name of company:

Name of individual:

Position of individual:

E-mail address of individual:

\section{Citigroup (Salomon Smith Barney}

Kosrow Dehnad)

Managing Director, Hybrid Products

kosrow.dehnad@ssbc.com

I am prepared for the participation of my organisation in this survey to be disclosed, but not my responses to individual questions or to any overall characterisation of my organisation's view.

YES $\quad$ (Please delete as necessary)

I would like to receive an electronic copy of the completed dissertation on Integrated Risk Management, which should be available in September 2000, at no charge.

YES

(Please delete as necessary)

Signature of individual:

JWH pp KD

Date:

$25 / 08 / 00$

\section{Section I - Turnbull}

\section{Answer 1}

Within the larger companies and at the highest level, yes (i.e. CEO's/CFO's), but not at lower levels. No knowledge of smaller companies.

\section{Answer 2}

There is some evidence of a change in philosophy towards risk management, but implementing change is difficult and often considered as involving too much hassle. Reorganisation requires cultural change, which is notoriously difficult to implement. The fact that risk crosses so many traditional boundaries within a firm is one of the main problems. Also, there is the question of personnel having their jobs at risk if they pass on the responsibility for risk management within their own are to elsewhere.

\section{Answer 3}


Clearly the accounting profession need to be involved, but not at the cost of an unbalanced or too narrow perspective. Any guidelines should be part of an overall and consistent framework of legislation and/or regulation. We must not lose sight of the fact that accurate data is a critical element of risk analysis and modelling and this is often best provided by the accounting area.

\section{Answer 4}

Treasury is the natural home, since a good treasurer will in any event have a good understanding of the business as a whole and good links with the operations, as well as having a good knowledge of markets and instruments. Insurance must also be integrated within the treasury department.

\section{Answer 5}

No view.

\section{Section II - Integrated Risk}

\section{Answer 6}

There may be some positive influence, but there are also many negative influences, e.g. FASB133 (requiring the marking to market of derivatives). Although this is a US accounting standard, there is a risk that the UK may follow suit and UK companies listed int eh US will anyway have to prepare their financial statements in accordance with US GAAP.

\section{Answer 7}

- No. Many of the premiums have simply been diverted from elsewhere. Also, where financial elements have been involved insurance companies have not been able to provide them internally.

- Again, FASB 133 requires the final form of any combined contract to be insurance. Things may change for the better, for example bank/insurance partnerships forming (but not necessarily where you would expect them, e.g. Credit Suisse/Withertur, where cultural issues seem to be a problem.

- Possibly

- An early change to FASB 133.

\section{Answer 8}

- Growing but slowly over the last five years, but FASB 133 makes it hard. Another phenomenon is that of dominant risks, e.g. jet fuel exposure in the airline industry, where it is hard to combine other, smaller risks that are uncorrelated.

- There may be some pick up in growth, but unlikely to be major.

- Early changes to FASB 133.

\section{Answer 9}

- $\quad$ The main problem seems to be one of culture, although again FASB 133 has had a negative impact. Given how few companies actually centralise risk management in all of its forms, it is 
just too hard in many cases to make the necessary people work together or even to have the same perspective (partly due to different backgrounds and educations). Even geographical dispersion of relevant personnel can cause a problem. In the current economic climate, risk management issues anyway tend to be secondary or tertiary.

- $\quad$ Probably, due to likely dip in corporate profitability.

- $\quad$ Changes in regulations, economic growth continuing.

Answer 10

Difficult to design standard integrated products. The $\mathrm{CFO}$ and the treasurer must be the prime targets in practice. 


\section{Details of Responding Organisation}

Name of company:

Name of individual:

Position of individual:

E-mail address of individual:
Deloitte \& Touche

Derek A Ross

Partner, Head of Treasury \& Risk Consulting, London

N/A

I am prepared for the participation of my organisation in this survey to be disclosed, but not my responses to individual questions or to any overall characterisation of my organisation's view.

YES (Please delete as necessary)

I would like to receive an electronic copy of the completed dissertation on Integrated Risk Management, which should be available in September 2000, at no charge.

YES

(Please delete as necessary)

Signature of individual:

JWH pp DAR

Date:

$24 / 07 / 00$

\section{Section I - Turnbull}

\section{Answer 1}

Broadly, yes, at least for the FTSE-100 companies, perhaps not so much the smaller ones. Boards have generally been pushed into action by their advisers if they have not been self-starters.

\section{Answer 2}

No sea change is apparent, but in part this is because of a heightened awareness of risk factors by large companies over the last decade or so. Turnbull may have accelerated this process, but by and large companies do seem to be modifying their behaviour and buying into the idea of enterprise risk management rather than simply paying lip service.

\section{Answer 3}


This delegation was really inevitable, there being no viable alternative. As soon as the issue became one of disclosure and reporting the finance function, and thus the finance director, became involved and the largest professional body of accountants (not just auditors) was the obvious body to carry out the work.

\section{Answer 4}

For reasons outlined in $\mathrm{Q} 4$ above, the $\mathrm{CFO}$ has to be the obvious person for most corporates. Also, in many corporates the group risk manager will anyway report directly or indirectly to the CFO. For financial organisations, however, it may be the head of group risk or the equivalent.

\section{Answer 5}

Most corporates consider increased compliance work an unhelpful distraction from their real business, notwithstanding greater interest in risk management generally. Of course, this view is not particularly shared by the accounting profession!

\section{Section II - Integrated Risk}

\section{Answer 6}

Not really. For many corporates the link between an enterprise approach to risk management and integrated risk management solutions will not be obvious. Even quite astute CFO's and others will find the rationale for integrated projects difficult to grasp and of those that do many will be naturally suspicious of the pricing underlying apparently 'bundled' products.

\section{Answer 7}

(i) If there has been it is certainly not obvious to those who are not closely involved with the insurance sector. (ii) There is no obvious trigger, so probably not. (iii) More rapid convergence between the insurance and capital markets than has taken place so far.

\section{Answer 8}

Clearly the growth in all types of derivatives in recent years has been enormous, but there is little obvious evidence that such products (e.g. 'quantos') are growing faster, possibly the reverse (based on audit evidence). Their market share is still very small, although much hyped. One possible exception is Asian (i.e. average rate) options, which are being used increasingly frequently for hedging earnings translation exposure. (ii) Again there is no obvious reason why there should be. (iii) A step change in the application of quantitative techniques by corporates.

\section{Answer 9}

For many companies it ought to be possible to reap many of the rewards of an integrated programme simply by using fully appropriate limits and deductibles with a conventional programme. Once this has been done it may be less likely that the economies of scale and/or scope by using a single supplier will outweigh the 'auction' advantage of buying the components on a disaggregated basis. One interesting hypothesis that could be tested, however, is that pricing inefficiencies are more likely to exist in the very high level excess layers that are more likely to be encountered with an integrated programme. 


\section{Answer 10}

This is doubtful. Clearly participants need to be aware of possible solutions to client problems, but the degree of tailoring is likely to be such that 'standard' products are hard to develop. As far as targeting is concerned, the CFO must remain the prime target in most corporates. 


\section{Details of Responding Organisation}

Name of company: $\quad$ Marsh

Name of individual: $\quad$ Scott Sanderson

Position of individual: $\quad$ Senior Vice President - Marsh Risk Finance

E-mail address of individual: scott.m.sanderson @ marshmc.com

I am prepared for the participation of my organisation in this survey to be disclosed, but not my responses to individual questions or to any overall characterisation of my organisation's view.

YES (Please delete as necessary)

I would like to receive an electronic copy of the completed dissertation on Integrated Risk Management, which should be available in September 2000, at no charge.

YES (Please delete as necessary)

Signature of individual: $\quad$ JWH pp SMS

Date:

March 27, 2000

\section{Section I - Turnbull}

\section{Answer 1}

No. Risk means very different things, and most of the risks considered have been those that are tradable or at least financial in scope. Its much easier to focus on identifiable variables that impact volatility than aspects that are inherently subjective and cannot be easily or rationally quantified.

\section{Answer 2}

I believe most organisations would like to approach the process to include a broader set of definitions and their related quantification. However, the process is complex and therefore expensive. My estimate would be that most organisations of substance would address those that they had to first, and supplement the process as time and budgets allow. I think the intention of most organisations is positive.

\section{Answer 3}


Yes - I suspect that the scope of the initial intention was control oriented, which has been traditionally handled by accountancy professionals. While I don't believe this should be the final approach, it was a logical place to start.

\section{Answer 4}

Committee approach, with the appropriate specialists in the group, probably lead by Financial director, who would likely have the best understanding of the impact of financial volatility. Such a committee should include treasury, operations, purchasing, R\&D and any other area where the impact of that part could result in material financial variation in the organisation's results.

\section{Answer 5}

Generally a good start, but needs further definition and standards.

\section{Section II - Integrated Risk}

\section{Answer 6}

Not really. While Turnbull may make people think in a more integrated way, Turnbull really only requires looking at individual risks, and not necessarily managing them systemically. The combination programs, to be effective, will need to be economically compelling in their own right - arrangements where the result of a rational buyer would be interested, regardless of the regulatory environment.

\section{Answer 7}

Multi-line/multi-year insurance policies (assuming no financial risk are included) came from a staring point 5-7 years ago of zero, became popular and interest levelled off, as they didn't provide a compelling economic purchase. They weren't notably less expensive, although they were somewhat, given the more efficient use of limits. As insurers tighten a marketplace, they will resist multi-year programs in an environment they perceive as an increasingly expensive. Thus a hardening market will become an impediment.

As financial and other risk elements are included, they will likely grow materially, as they will be taking in new risks not previously in insurance. However, the process will be slower than initially expected, as most users of such products remain traditionally organised and will have difficulties making decisions and applying programs across budgetary units, even though they may make tremendous sense in the view of the organisation as a whole.

\section{Answer 8}

Basically covered in \#7 above. Tremendous opportunity, have rational economic underpinning, but are difficult to digest in a traditionally organised company.

\section{Answer 9}

(1) Slow in coming due to a number of reasons. On the user side, the ability to analyse the economic value resides in numerous parts of an organisation, making the decision process slow. Each party reviews in the context of their experience and expertise only. This to 
achieve a decision, there must be a leader with a view of the overall impact. These leaders, who can cut across corporate boundaries have been rare, and have had a tendency to move to other positions before the project is completed. Organisations have also had a tradition of timing hedges to gain added income, rather than use a mechanistic approach. RiskFusion structures are inherently mechanistic. On the market side, they, too, must have an integrated approach to assessing and assuming risk. In their traditional casualty, marine, property, etc divisions, there is inherent compartmentalisation that inhibits effectively underwriting the exposures. Markets are now frustrated that more have not completed, making the desire to organise effectively a low priority. The economics remain compelling, but the practical application makes the arrangements difficult to complete.

(2) There will be an acceleration, but it will be slower than initially expected, with higher levels of interest once the process becomes more common and accepted.

(3) Market withdrawal, more difficult accounting rules, and continued practical acceptance of the notion that derivatives can be traded for added profit, thus offsetting economic advantages of these designs.

\section{Answer 10}

A standard set of products could be created, but would need to have tremendous flexibility. Today, each market handles as a one-off, making the modelling and pricing process extremely inefficient. If I were making these decisions, I'd also focus on creating protections for commodities and FX where there were inefficient markets due to thinness or complete lack to trading, thus bringing the additional value of not having a face-to-face comparison to derivative equivalents.

The target would likely be the Treasurer and/or CFO, assuming there is no Chief Risk Officer at a high enough level. Commodity exposures are more problematic, as they are typically under the control of purchasing, not treasury. The CEO may be interested, but it would be a rare CEO who would understand and appreciate the complexity and opportunity. As the financial professionals are ones who are intimately involved with the management of volatility, it would be logically be their area. 


\section{Details of Responding Organisation}

Name of company: $\quad$ McKinsey - but I am responding as an individual

Name of individual: $\quad$ Martin Markus

Position of individual: $\quad$ Associate Principal

E-mail address of individual: martin_markus@mckinsey.com

I am prepared for the participation of my organisation in this survey to be disclosed, but not my responses to individual questions or to any overall characterisation of my organisation's view.

YES (Please delete as necessary)

I would like to receive an electronic copy of the completed dissertation on Integrated Risk Management, which should be available in September 2000, at no charge.

YES (Please delete as necessary)

Signature of individual: $\quad$ JWH pp MM

Date: $\quad 14$ August 2000

Section I - Turnbull

\section{Answer 1}

No.

Answer 2

I do not expect rapid fundamental change. I think there will be significant change in the medium term as new approaches take hold.

\section{Answer 3}

It shows how the risk management profession has failed to rise to the challenge of new forms of risk.

\section{Answer 4}


N/A for me. I would expect most CEO's to put this in finance function, where increasingly the operational risk function will report.

\section{Answer 5}

No.

\section{Section II - Integrated Risk}

\section{Answer 6}

No. I think the real driver for integrated cover will be (1) price compared to traditional cover (2) ability of providers to explain the benefits convincingly to finance directors.

\section{Answer 7}

Yes to (1) and (2). If rates harden then the incentive to lock in prices now through multi-year covers will increase; the converse is also true. As with integrated cover, there need to be tangible financial or service benefits from this approach for it to have real impact. I believe these exist but they depend on comparative market prices and the industry's ability to develop and articulate the financial case.

\section{Answer 8}

Yes to (1) and (2) although I do not think the numbers will be very large. Financial solutions are likely to be significant in some specific niches e.g. environmental liability, residual value. Macro solutions like e.p.s. or general balance sheet protection are unlikely to be economic unless related to specific risks.

\section{Answer 9}

(1) The main problem is price - not yet shown definitively these deals are more cost effective than separate cover. A secondary problem is that few people in the traditional risk management industry have really mastered the technology, even though it exists.

(2) Yes, but relatively slowly.

(3) Rapid hardening of premium rates alongside acceleration of sophistication among both buyers and sellers of risk management.

\section{Answer 10}

Yes, I would put a high priority on developing a suite of integrated products along with specific products for particular needs e.g. environmental, residual value etc. I would direct this at the CFO. 


\section{Details of Responding Organisation}

Name of company:

Name of individual:

Position of individual:

E-mail address of individual:
PricewaterhouseCoopers

Nigel Buchanan et al

Partner

I am prepared for the participation of my organisation in this survey to be disclosed, but not my responses to individual questions or to any overall characterisation of my organisation's view.

YES (Please delete as necessary)

I would like to receive an electronic copy of the completed dissertation on Integrated Risk Management, which should be available in September 2000, at no charge.

YES (Please delete as necessary)

Signature of individual: $\quad$ JWH pp NJCB

Date:

$09 / 08 / 00$

\section{Section I - Turnbull}

\section{Answer 1}

Most companies have understood the implications of Turnbull "in spirit". They recognise what Turnbull is trying to achieve and the ramifications for the business. However, the majority of companies are not, at present, seeking to comply with the spirit. Most are applying the minimum to allow them to meet the requirements and achieve compliance with the guidelines.

The reasoning for this is probably two-fold:

- many companies have not ben able to identify major benefits flowing from a risk management programme (in terms of value-added) and are therefore reluctant to invest;

- the models and frameworks for enterprise-wide risk management are still developing and, in many instances, rely on judgmental or qualitative data. In an analytical and performance-driven environment, executives naturally feel uncomfortable with basing decisions on such data.

In the future, an enterprise-wide approach may become more commonplace as: 
- $\quad$ tools become more sophisticated;

- $\quad$ leading companies are able to demonstrate the value of such an approach;

- a major corporate disaster causes regulators, etc. to review the company's risk management procedures and disclosures and what they really meant.

\section{Answer 2}

As above, most companies have not yet committed to the enterprise-wide philosophy in practice. The most common practice is to do the minimum necessary. However, there are a number of companies where a much more pro-active approach is taken and the results of the risk management process applied to improve business performance, management and strategy.

\section{Answer 3}

The result has almost certainly raised questions about "jobs for the boys". However, what is recommended is inherently sensible, if a little too wrapped in accounting jargon, and therefore I do not think that there has been much disagreement with it in principle. I think that such a document and its contents would have held more sway had it been put together by a group of Chief Executives, Non-executive directors and leading analysts. It would have been more strategic in nature, may have provided greater flexibility in approach and would have been more targeted at the real needs of executive management and investors.

\section{Answer 4}

The obvious answer is the CFO with the support of business unit CEO's. Despite recent changes and movements, Internal Audit is still generally regarded as uncommercial and backward looking. It is vital the business unit CEO's are committed and understand the implications of the guidance. While responsibility might be delegated to the Group CFO, the Group CEO should have a direct responsibility for ensuring the commitment and buy-in of their senior management team.

\section{Answer 5}

The Turnbull guidelines in principle make good sense. In practice, however, until businesses and, most importantly, investors can see real benefits flowing from the application of the guidelines, they will remain on the "sideline". In general, the current level of disclosure of risk management practices by businesses tends to be "boiler-plate" and does not add much to the reader's real understanding of the business. Turnbull will only really be taken seriously when executives and investors are able to see it is making a significant difference.

\section{Section II - Integrated Risk}

\section{Answer 6}

The main purpose of "double trigger" policies is to restrict the activation of the insurance to a sequence of events that causes significant loss (with a reduction of premium compared to "conventional trigger" policies). As well as limiting the coverage of smaller claims, the less desirable outcome is that claims become difficult to adjust.

I would not expect to see much use of double triggers in existing areas of insurance while premium rates remain at current levels. In other areas of financial and business risk, I would expect double triggers to 
become increasingly common, albeit that it is very difficult to incorporate financial risks in a manner that makes them insurable. This is because many of the areas of significant business risk, the causes are not outside the control of management (i.e. fortuitous) and the losses that may be suffered could be reversed (e.g. fall in share price).

Insurance is one of several possible responses to identifiable organisational risks. It may prove a driver to develop integrated solutions in a few cases, but we do not see it having a general, positive influence in this regard.

\section{Answer 7}

- The take-up of multi-line, multi year policies has been small. The principal reason is that rates for conventional, annual policies have been low, making multi-line alternatives unattractive. There is also a large "inertia factor" within the insurance industry, resulting from insurers' reinsurance constraints, and different lines being underwritten separately by different underwriters.

- In addition to (i), the other factor which, in my view, will continue to restrict the growth in multi-line, multi-year policies is the speed of corporate change. It is difficult to operate multi-year policies when the underlying business and associated risks are in flux.

- Although we are cautious in predicting significant uptake of these policies, a hardening of insurance rates, with a consequent increase in use of self-insurance and captives could bring about change. In order for multi-line, multi-year policies to be more attractive insurers must offer packages that are competitive with "unbundled" solutions, placed with one or several insurers. An increase in the consolidation of insurance companies, coupled with an increase in the market power of insurers compared to brokers, might also be an agent for change in this area.

\section{Answer 8}

- Not to a significant extent; growth has been isolated and piecemeal.

- Various factors make this unlikely: the effect of insurance premium tax on transaction costs, the accounting, tax and regulatory environment (which makes the transformation of financial to insurance risk problematic) and lack of standardisation of the risks concerned (with a consequential need for, and cost of, professional assistance).

- Greater take-up leading to the development of standardised insurance products.

\section{Answer 9}

- The large input of professional advice needed makes these deals expensive. This is due to the accounting, tax and legal issues that must be addressed.

- The emergence of specialist niche underwriters who really understand the risks involved suggests that there will be substantial development within these niches. An example is weather derivatives.

- Adverse accounting or regulatory charge, poor underwriting results on the risks concerned.

\section{Answer 10}

The only way to ensure a high adoption of integrated products is as you suggest, to "standardise" them, insofar, as is possible, thereby making them economic. 


\section{Details of Responding Organisation}

Name of company:

Name of individual:

Position of individual:

E-mail address of individual:
Prudential Group plc

Mark Butterworth

Head of Group Risk

mark.butterworth@prudential.co.uk

I am prepared for the participation of my organisation in this survey to be disclosed, but not my responses to individual questions or to any overall characterisation of my organisation's view.

YES $\quad$ (Please delete as necessary)

I would like to receive an electronic copy of the completed dissertation on Integrated Risk Management, which should be available in September 2000, at no charge.

YES

Signature of individual:

Date:

\section{Section I - Turnbull}

\section{Answer 1}

I believe that the requirements of Turnbull are quite well appreciated - there may be some listed companies that are not yet fully tuned in. What is less well appreciated is what it all really means, and the sustained commitment to effective risk management operations in companies that will be required.

\section{Answer 2}

No I do not foresee that CG/Turnbull requirements will in themselves change those senior company managers/directors who have not already established good RM. However, investor pressure, non-executive directors' views and the wider spread of knowledge should push these companies towards improving their RM practices.

\section{Answer 3}


Yes, it would have helped if a wider membership was brought in to the Turnbull committee. It fact Nigel Turnbull did consult with AIRMIC, especially in the final stages, but this only marginally helped to ease the "financial controls" flavour of the guidance.

\section{Answer 4}

The Audit Committee, who should draw upon a risk management roundtable within the company - consisting of auditors, risk management, legal, safety, quality etc etc.

\section{Answer 5}

Yes, in the consultation process, AIRMIC recommended that the public reporting of risk should include a discussion of how the business finances residual risk, i.e. what reserves/contingency funds/insurances are in place to meet the costs of when things go wrong. The benefit of this would be to understand the resilience of the business to risk events and it would make the directors think more clearly about quantifying residual risk.

\section{Section II - Integrated Risk}

\section{Answer 6}

No. There is certainly a connection between CG and risk financing but it is tenuous. See also Q5! These risk financing structures will develop independently.

\section{Answer 7}

(i) Yes (ii) Not materially, in a hardening market there is less pressure on insurers to offer financial benefits for these deals, particularly discounts for multi-year polices (i.e. instead of 3 years insurance at 2.4 times the annual rate, the multiple may be $2.8,3$ or even higher than 3 ). (iii) The market does not harden and competitive pressures keep multi-year/line polices most competitive.

\section{Answer 8}

(i) Yes. (ii) Yes. (iii) If large losses come along some players may get cold feet and pull out of the market, leaving risk managers with fewer competitors and fewer options.

\section{Answer 9}

(i) These structures are very specialised - also I believe there have been more than your question indicates. (ii) I see growth as steady - no real "acceleration". (iii) A severely hardening market leading to risk managers looking more determinedly at alternative structures.

\section{Answer 10}

(i) Standard suite? Yes I would tend towards this idea, but keeping a flexible approach as well!. CFO. 


\section{Details of Responding Organisation}

Name of company:

Name of individual:

Position of individual:

E-mail address of individual:
Swiss Re

Paul Franklin York

I am prepared for the participation of my organisation in this survey to be disclosed, but not my responses to individual questions or to any overall characterisation of my organisation's view.

YES (Please delete as necessary)

I would like to receive an electronic copy of the completed dissertation on Integrated Risk Management, which should be available in September 2000, at no charge.

YES

Signature of individual:

Date:

$23 / 08 / 00$

\section{Section I - Turnbull}

\section{Answer 1}

Not all of course, but in my view by a larger number than one might imagine. UK listed companies have often be thought of as somewhat slower to adopt change than their opposite number in America, but with the companies that I deal with on a regular basis - Utilities and Metals primarily - I have found their approach to be quite sophisticated and the Turnbull Guidelines are not a major issue in terms of compliance.

\section{Answer 2}

My firm belief is that "risk management" will now come of age as the CEO's and CFO's recognise that the "Insurance Man" is not the answer required to meet the challenges of really understanding the risks of the firm. Several major firms now have a CRO (Chief Risk Officer) who along with traditional risk management issues to deal with, will also be required to bring to the table a formal "financial risk management" set of tools in order to do the job. Solid understanding of hedging, balance sheet issues, 
and traditional risk management issues will be enhanced by a CRO who also has a general business background to draw upon. This person will report to the board as do the CEO and CFO. Firms that adopt this approach will see themselves with a significant competitive advantage in the near term.

\title{
Answer 3
}

Nothing is ever perfect, and since it is the accountancy/auditing firms that have to apply the measurement, their participation in the design and drafting of the guidelines is/was essential.

\section{Answer 4}

The board has ultimate responsibility - as the CEO I would entrust the CRO with the job.

\begin{abstract}
Answer 5
No, except a question as to whether or not it will improve the individual shareholder knowledge of the company or only be of benefit to the institutional investors.
\end{abstract}

\section{Section II - Integrated Risk}

\section{Answer 6}

Despite the hype, there is very little activity in really innovative approaches to risk. Our experience is that there is great resistance from the broker market, and from the companies themselves, as when done properly, a new program will cut across all areas of responsibility within a company. This results in a good deal of internal questioning as to the absolute benefit of such a program. The CFO has his staff issues to address, the Treasurer has his and the Risk Management group have their issues to deal with and in a truly integrated approach, it is felt that someone loses out in the process. We are seeing more interest, but in real

numbers, we are far below expectations. Most importantly, in doing a large ( $£ 1$ Billion) program, one company can not take on the entire deal, but must syndicate the deal to a number of other players, and recent experience has shown that very few are willing to actually participate with significant capacity - banks and insurers/reinsurers.

\section{Answer 7}

Current market conditions have made multi-year/multi-line products less attractive. Premium volume from these products is much lower than industry forecasts and this continues today. View on the future is somewhat mixed, but generally positive. The market is really starting to harden and the attractiveness of these products may increase, although my personal belief is that they will never achieve the forecast heights thought possible a few years ago. What could make my forecast wrong? 1.) The market does not harden to extent believed at the moment. 2.) Much heavier use of "pure financial" products to address risk issues therefore making MY/ML products less attractive. 3.) Multi-year/Multi-line products develop that actually save the client company money over the term of the contract (not always the case at the moment.)

\section{Answer 8}


The use of contingent capital products has increased dramatically over the past few years with a real increase this year. Reasons are that insurance/funding approaches blended with contingent capital products can provide necessary protection at very reasonable cost and repayment terms of the "contingent capital" component are attractive when compared to the average market pricing of debt instruments. I believe that we will see a real increase in the use of blended financial/risk products over the coming years and in terms of forecast issues on this, I do not believe that any event, except for a huge increase in interest rates, will dull the interest in going forward with these innovative approaches. One product grouping that really addresses balance sheet issues well and can be understood by the CFO, whereas some pure insurance driven products do not attract the same interest level from that position.

\section{Answer 9}

Please see comments above, as they have application here as well. Again, with the hardening of the market, we believe that we will see more activity. There are at least 4 other deals that we know of that have been done since Honeywell, and several others in the works now. Personal belief is that we will see more of this type of deal along with the "Contingent capital" type of programs going forward. Forecast issues same as Q8.

\section{Answer 10}

Ideally the CEO, but that person rarely has the time to devote to these issues. With £100M to £1Billion being the norm in these types of programs and with an element of debt or equity financing attached, the $\mathrm{CFO}$ has to be involved. Most CFO's have the time to devote to an issue that can have a significant impact on their earnings or balance sheet (Note: you will find several examples of this in the Prakash book.) In terms of developing a "standard suite" of products, I do not believe that we are close at this time. We can have a general understanding of the types of products/solutions that may work in certain situations, but in this area, one must be really able to adapt to the individual needs of a client company and no one solution can fit the bill for every company. For example, a utility might be interested in protecting itself against wild swings in the price of electricity, or the volume risk associated with weather. They might also have issues with stranded assets or decommissioning of old plant that need to be addressed. This is vastly different from a building materials company that has warrants issues with building products or a metals company that needs help with long term pollution clean up issues or long term raw material hedges to "fix" a perceived problem. The answer is to have a group of people with a skill base that have the ability to analyse issues and create solutions to fit the problem presented. This skill base has to include everything from traditional risk covers to macro/micro economic research and everything in between. The issue then is to be able to present the solution to a panel of banks and insurers in a concise manner that results in a program that solves the problem of the client company and on a medium term basis -3 to 5 years. 


\section{Details of Responding Organisation}

Name of company:

Name of individual:

Position of individual:

E-mail address of individual:
TRW Inc.

Paul Pope

Assistant Manager, Risk Management

I am prepared for the participation of my organisation in this survey to be disclosed, but not my responses to individual questions or to any overall characterisation of my organisation's view.

NO (Please delete as necessary)

I would like to receive an electronic copy of the completed dissertation on Integrated Risk Management, which should be available in September 2000, at no charge.

YES (Please delete as necessary)

Signature of individual: $\quad$ JWH pp PP

Date:

August 18, 2000

\section{Section I - Turnbull}

\section{Answer 1}

No. The concept of risk is not viewed consistently from company to company or even consistently within a company (e.g. static vs. dynamic risk, macro vs. micro, industry vs. economy, etc.). Until such time 'risk' takes on a broader and more consistent meaning, the implication will not be full appreciated.

\section{Answer 2}

More likely to do the minimum versus a change in approach. Unfortunately, guidelines generally tend to set the ceiling for performance versus the floor for performance. Those companies that view risk in a broad and structured manner will do so not because of Guidelines, but because of perceived value/competitive advantage.

\section{Answer 3}


The accountancy profession tends to focus on the past and on an extremely narrow segment of risk. As such, their view of risk probably does not make them particularly qualified to deal with risk management in its broadest sense.

\section{Answer 4}

Internal Audit

\section{Answer 5}

No strong views.

\section{Section II - Integrated Risk}

\section{Answer 6}

It may cause further inquiry, but I do not feel it will have a "significant" influence on the speed of development and acceptance of such products. The reason for this view is that most managers do not want to change and do not have the desire/ability to fully understand/implement such policies. This applies to managers within industry, brokers and insurance companies.

\section{Answer 7}

While there has been some growth, I do not believe it has been high.

I do not believe growth will be high over the next 5 years, the insurance industry has/is consolidating and the pressure for them to develop new products will stagnate.

Underestimate the ability/desire for change by risk manager/insurance buyers.

\section{Answer 8}

See 7 i) above.

See 7 ii) above.

Underestimate financials institutions (other than insurance cos.)

\section{Answer 9}

- There is a difference between the technology existing and the existence of the intellectual framework for analysing these risks. While the technology exists, arguably the framework is lacking. How risk is valued/costed internally also has a dramatic impact in terms of what a company is willing to pay for an insurable/financial risk management solution. If a company is currently hedging foreign exchange in the financial markets, their view of what they are willing to pay will be different from a company that does not hedge at all.

- I I believe there will be acceleration as tools/technology becomes more user friendly and more common.

- A dramatic shift in the insurance market that causes traditional insurance products to be highly profitable.

Answer 10 
The reality of integrated risk management products is that there is very little that is standard. One of the problems from an insurance company perspective is that they generally want to standardise as much as possible and integrated risk is somewhat contrary to that goal. Marketing efforts depend on how 'integrated' the approach. If simply financial and insurance risk - the CFO. If anything broader - the CFO or CEO. 


\section{Details of Responding Organisation}

Name of company:

Name of individual:

Position of individual:

E-mail address of individual:

\author{
United Insurance Brokers
}

Roy Dyton

Director

Roy_Dyton@uib.co.uk

I am prepared for the participation of my organisation in this survey to be disclosed, but not my responses to individual questions or to any overall characterisation of my organisation's view.

YES $\quad$ (Please delete as necessary)

I would like to receive an electronic copy of the completed dissertation on Integrated Risk Management, which should be available in September 2000, at no charge.

YES

(Please delete as necessary)

Signature of individual:

JWH pp RD

Date:

$21 / 08 / 00$

\section{Section I - Turnbull}

\section{Answer 1}

None of the UK companies with whom I have had dealings during the past decade have ever taken the initiative in seeking from me any information regarding possible deficiencies in that organisation's insurance or risk management programme. Equally, in my capacity as a Governor of the Institute of Risk Management I cannot recall information coming my way suggesting that a sea-change of attitude had occurred following Turnbull. While a few of my risk manager contacts are clearly charged with taking an Enterprise wide view of risk related issues, it appears they are very much in the minority and I am forced to conclude that a majority of UK companies have yet to appreciate the implications of Turnbull.

\section{Answer 2}

Human nature is such that I cannot see a rapid change of emphasis to embrace enterprise risk management. All organisations are subject to performance pressures that will detract from 
implementation and, at the same time, there is a shortage of competent practitioners possessing the necessary skill levels to achieve effective implementation.

\section{Answer 3}

The accountancy profession is already the established "policeman" of company affairs and possesses relevant financial and legal training. It is only natural for them to be regarded as the "natural" resource suitable for preparing such guidelines.

\section{Answer 4}

In relation to Turnbull compliance, a key question must be whether to target position or personal suitability? There is no single professional training that seems currently to be suitable for effective oversight of company wide issues, although I see academic specialisation in Corporate Governance issues has recently been established in some British Universities.

- Few accountants seem to possess the requisite skills to look beyond basic book-keeping criteria to appreciate the economic realities determining risk to corporate assets and performance but a sound grasp of accountancy disciplines are fundamental to effective operation.

- "Risk Managers" readily lay claim to this high profile role but a majority seem to have developed from safety and insurance disciplines and thereby lack a basic grasp of high level finance criteria seemingly vital for Turnbull compliance.

- Internal Audit has a designated control function but usually this is set against established performance expectations - whereas Turnbull compliance must also anticipate the need to monitor the unexpected in non-financial fields such as technology, sales and corporate ethics.

- Compliance tends to be an invidious responsibility because superiors naturally prefer to hear good news rather than tales of woe and foreboding. The position and its reporting line therefore need to be established in such a manner that independence from undue influence is established.

I would allocate responsibility for Turnbull compliance to the Finance Director and probably then seek to establish a committee of non-executive directors to oversee this function.

\section{Answer 5}

No.

\section{Section II - Integrated Risk}

\section{Answer 6}

The process of assessing risks likely to inhibit attainment of corporate performance objectives must, logically, point to the likelihood of a growth in the number of "double-trigger" insurance products. In that sense, Turnbull can be seen as a potential source of growth of such products but, to the extent that implementation is likely to be slow it seems unlikely that any growth will be particularly dramatic.

\section{Answer 7}


I believe there has been a growth in multi-line/multi-year insurance products due to the fact that some traditional insurers are seeking to reduce acquisition costs by tying policyholders to themselves with 3 or 5 year policies. Policies have traditionally been issued for annual periods and it is difficult to understand the rationale for this, other than the fact that it has been an accident of history. With pressures of competition to reduce premiums and also to reduce expense ratios, it is to be expected that such products will grow in popularity during the coming five years.

This forecast could be wrong if:

- $\quad$ Policyholders anticipated premiums would fall significantly in coming years.

- $\quad$ The reinsurance market insisted on retaining annual contracts and it was anticipated that their charges would grow significantly.

- $\quad$ Legislative obstacles were placed in the way of multi-year policies.

\section{Answer 8}

I am inclined to believe there has been a growth in multi-line financial products during the past five years but have access to insufficient information to be confident in this statement. Equally, I believe it likely future growth will continue by reason of the expansion in sophistication among buyers of such insurance products, especially if there is a greater integration between the traditional treasury and insurance related corporate functions.

This forecast could be wrong if:

a) Fiscal barriers were placed in the way of such products.

b) A well publicised failure of an insurance/financial product occurred

\section{Answer 9}

An absence of integration in corporate risk management activities; conservatism; and relatively cheap conventional insurance.

\section{Answer 10}

If I was confident of knowing the answer to this question, I would keep the answer to myself and form my own company! 


\section{Details of Responding Organisation}

Name of company: $\quad$ United Insurance Brokers Ltd

Name of individual: $\quad$ Simon J Newton

Position of individual: $\quad$ Divisional Director

E-mail address of individual: $\quad$ simon.newton@uib.co.uk

I am prepared for the participation of my organisation in this survey to be disclosed, but not my responses to individual questions or to any overall characterisation of my organisation's view.

YES (Please delete as necessary)

I would like to receive an electronic copy of the completed dissertation on Integrated Risk Management, which should be available in September 2000, at no charge.

YES (Please delete as necessary)

Signature of individual: $\quad$ JWH pp SJN

Date: $\quad 22 / 08 / 00$

\section{Section I - Turnbull}

\section{Answer 1}

It appears that a general thrust towards greater accountability is being sought, but as in all initiatives progress will be slow. As you drop down the list of FTSE companies I believe that the appreciation of this will clearly diminish.

The Financial Services and Markets Act will lead people away from our arena "Insurance" and towards other products, and the management of risk will be seen in its broader sense with insurance, regrettably, not playing in the premier league.

\section{Answer 2}

Again from an insurance perspective I believe that the operation that requires management will drive the controls. Those that have chosen already to adopt a structured approach will stay, those that have not will only change when the diversity of the business forces change.

\section{Answer 3}

Yes. Finance and financial risk management, which is much closer to the day to day operations of a 
company and, therefore, the P\&L account, do and should drive. In many respects Insurance is static by comparison. On a final note, Insurance has not been lauded as one of the "City Professions", hence, perhaps, this delegation.

\title{
Answer 4
}

Treasury.

\section{Answer 5}

From my insurance perspective, I did not see any mention of insurance.

\section{Section II - Integrated Risk}

\section{Answer 6}

No. These in the past have been market driven and, as new products, generally carried an element of risk which could be unpalatable to those following Turnbull.

\begin{abstract}
Answer 7
ii No. These products have sucked premium out of the market as a whole, moreover, if we look at the history behind these policies we can see that at firs they relied on reinsurance to drive them and this was an inefficient use of capacity - as the markets developed, these policies migrated to the traditional markets and the multinational composite insurers took them over, but the overall principle has remained "buy two lines and get another for free".

ii No. These policies have now become standard, they will continue and will follow market trends, albeit with the new assureds gaining a saving over the traditional approach on the purchase of cover.

ii I do not see the above as a forecast, however to say 'yes' to (ii) above would require major realignment in the markets, with clients seeing the traditional mono-line approach to purchase being seen as more advantageous.
\end{abstract}

\section{Answer 8}

I am not familiar with these products so I cannot comment.

\section{Answer 9}

- Even Honeywell did no answer all it set out to. Financial legislation, especially in the US (FASB), has limited the ability of the financial markets to use 'capacity' for insurance related solutions. The global picture in my mind is that these solutions can work in a professional (i.e. reinsurance) environment) - be it bonding/spread loss - as the premium spend and the risk portfolio need to be of a size to warrant this approach. The list is very short from the insured versus reinsured perspective - even the initiatives of the larger broking houses (i.e. Aon and its CatEPut scheme) have not generated the success that the excitement in this relatively new field would suggest.

- $\quad$ Risk management almost drives the ultimate client towards seeking a goal which avoids the need for risk transfer - many major corporations have gone down this road and more will follow. The low-end transfer financial services could re-emerge as solutions if markets harden and spread loss could start to offer an alternative. However, I think the insurance market will need to increase its base cost two to three fold before this alternative becomes real. If this occurs, then the flurry of alternative products will emerge.

- If the mid-market follows the lead set by major corporations and the balance sheet cannot support 
the risk when it materialises, then companies might seek to use insurable/financial risk management tools as a means to trade out of an assumed position inherited from risk retention.

\section{Answer 10}

My view is that the insurance markets have traditionally put barriers between the buyer and seller. This has slowed the development of the market and caused, in part, the low esteem with which it is held. I would seek to achieve greater transparency which I would hope would allow the buyer and seller to develop new products with real value, and true organic growth will occur. My understanding is that in this paper we are looking very much at the high end of the market - this area wants bespoke products and an open market. The target area in the client organisation would have to be broad and would depend on which area housed other risk management functions. 


\section{Details of Responding Organisation}

Name of company:

Name of individual:

Position of individual:

E-mail address of individual:
Willis

Terry Pey

Principal - Risk Solutions

peytb@willis.com

I am prepared for the participation of my organisation in this survey to be disclosed, but not my responses to individual questions or to any overall characterisation of my organisation's view.

\section{YES (Please delete as necessary)}

I would like to receive an electronic copy of the completed dissertation on Integrated Risk Management, which should be available in September 2000, at no charge.

YES (Please delete as necessary)

Signature of individual:

JWH pp TP

Date:

09/08/00

\section{Section I - Turnbull}

\section{Answer 1}

A "systematic" approach to risk management in its widest sense is not the biggest challenge. Turnbull talks about "embedding" risk management within an organisation. This is the area that is causing our clients (those that embrace the concept) most problems. Please see the attached "flyer" and the integration model that it features.

Have the implications of Turnbull been fully appreciated? A minority of companies have fully appreciated the implications. Please see the attached survey response.

Many will be forced to do no more than the bare minimum because:-

- $\quad$ They do not take risk management seriously anyway and see Turnbull as bureaucracy

- $\quad$ They are engulfed by "initiative overload" and have not highly prioritised Turnbull relative to other issues

- $\quad$ They do not understand "embedding"

- $\quad$ They do understand "embedding" but have insufficient time in order to achieve the necessary 
culture change before next reporting.

It has probably escaped companies' notices that the Financial Services Authority have taken over supervision of the Listing Rules from the London Stock Exchange. Therefore, a careless attitude to disclosure could conceivably be regarded as a misleading statement under Section 47 of the Financial Services Act (as leading to the creation of a false market in securities). This could have serious personal ramifications for Directors.

And don't forget the Institutional Voting Information Service, Investor Protection Committees and PIRC. It only needs one high profile case to open the flood gates of regulation.

\section{Answer 2}

For most companies, to fully embrace Turnbull, and to embed risk management in its widest sense into a company, requires a cultural, not just a procedural or organisational change. This probably takes $2-3$ years. See above.

- This will depend on the prevailing culture and ethos of the organisation. For example, it is likely that those in retail will just tick the box.

\section{Answer 3}

Yes - conflict of interest. Good business for their consulting arms. How can the auditors objectively sign off on the client's corporate governance statement without implicating their own colleagues.

- However, it would have been difficult to visualise an alternative as the management science of risk management has many guises. In contrast the accountancy profession has a standardised persona and a statutory role under the Companies Acts.

\section{Answer 4}

Finance Director would probably be our practical choice. In practice, FD's, Heads of Internal Audit and Company Secretaries have the responsibility - probably in that order.

Enclosed is a copy of a recent Deloitte Touche briefing, which summarises the results of their survey/research. This shows that Heads of Internal Audit are the predominant lead on Turnbull, but in the immortal words of Mandy Rice Davies; they would say that, wouldn't they!

- (The ideal would be the Chief Risk Officer if there is one. Alternatively, someone neutral to the selection of solutions. Neutral means not unduly biased towards risk financing e.g. Insurance Manager, Treasurer). Arguably vesting responsibility with Internal Auditors creates a conflict of interest?

- I would avoid giving principal responsibility to Internal Audit as this creates a conflict of interest.

\section{Answer 5}

See Above.

\section{Section II - Integrated Risk}

\section{Answer 6}


Turnbull will have a positive influence on the speed of development and acceptance of such products. However, we are talking about a very small market place at present. Bear in mind that our experience of running Strategic Risk Assessments projects is that only a 20\% of "business risks" are "insurable" in any recognisable way.

Certainly, Turnbull has been a contributing factor for the increased interest in risk financing techniques that address unconventional, business critical risks or key business drivers. Other factors are just as significant - such as the fact that insurers will write these deals now. If they are feasible and add value people will look at them.

- The impact of Turnbull per se, will be less because the accountancy profession are leading the charge and have a blind spot where insurance and financial risk management are concerned (both of which are considered "specialised" and to be kept in the box).

- Also, risk financing solutions are viewed suspiciously by the corporate finance crowd - they know that risk finance means volatility reduction and therefore the potential to dampen profits. The investor's view of risk via betas and CAPM needs to be reconciled with the Director's view. This hasn't happened yet - but we're working on it!

\section{Answer 7}

(iv) This is not new. In every "soft" market phase there has been an upsurge of interest in long-term cross class programmes. They have been used for more than 10 years. (Recent innovations, this time round, are sharing of limits and, sometimes, a blended finite layer. These are details, however). In terms of above "average premium growth" - yes, a number of these deals have been placed. Premiums have actually fallen, and the premium has come from the traditional mono-line coverages.

The vast bulk of premium is still written on a mono-line basis (even if on a long-term deal with the same insurer).

- Much slower. Hard market for next 2 years.

- Insurers not reacting as predicted.

\section{Answer 8}

- In terms of multi-line financial risk management products, the premium growth has been such that the needle has barely flickered on the dial. Very few deals have been placed.

A significant volume of non-conventional/ART premium has been placed. Almost invariably, however, these deals have been specifically focused on particular and discreet risk areas. Many have had the effect of credit enhancing deals.

- Definitely.

Multi-line/multi-year programmes covering broadly conventional risks (see Q7) will be placed/unbundled according to traditional insurance market dynamics.

In looking at new financial risks the dynamics are changing. The capital markets and insurance markets are converging and overlapping (eg. weather, default swaps).

- No answer. 


\section{Answer 9}

- In part, language is the problem. Treasury and insurance risk management are like two nations divided by a (allegedly) common language. Whoever bridges the comprehension gap will win the prize. Also, the technology may have existed: it doesn't necessarily work well in practice.

Yes - but only where the right business drivers can be separated out.

No answer.

\section{Answer 10}

No, I think the answer lies in being able to model financial structures. The issue is one of modelling competence and market knowledge as well as being able to quantify such arcane concepts as risk appetite and tolerability (see Tversky et al). (ii) [CFO]. 


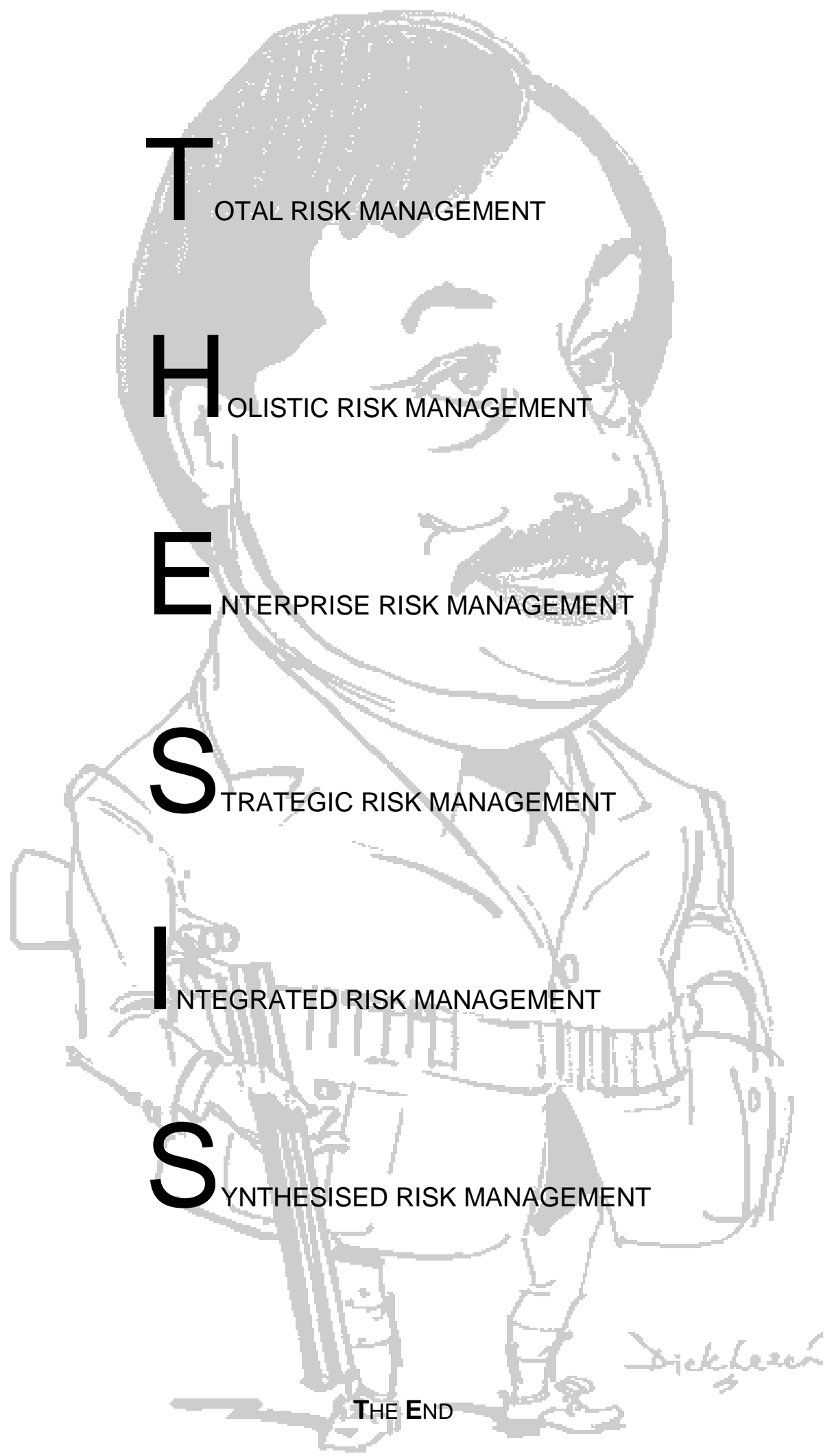

